\title{
Evaluation of subcooled MQL in CBN hard turning of powder-based Cr-Mo-V tool steel using simulations and experiments
}

\author{
Sampsa V.A. Laakso ${ }^{1,2}$ (D) Dinesh Mallipeddi $^{1} \cdot$ Peter Krajnik $^{1}$
}

Received: 19 April 2021 / Accepted: 19 August 2021 / Published online: 7 September 2021

(C) The Author(s) 2021

\begin{abstract}
Metal cutting fluids for improved cooling and lubrication are an environmental risk and a health risk for workers. Minimizing water consumption in industry is also a goal for a more sustainable production. Therefore, metal cutting emulsions that contain hazardous additives and consume considerable amounts of water are being replaced with more sustainable metal cutting fluids and delivery systems, like vegetable oils that are delivered in small aerosol droplets, i.e., via minimum quantity lubrication (MQL). Since the volume of the cutting fluid in MQL is small, the cooling capacity of MQL is not optimal. In order to improve the cooling capacity of the MQL, the spray can be subcooled using liquid nitrogen. This paper investigates subcooled MQL with machining simulations and experiments. The simulations provide complementary information to the experiments, which would be otherwise difficult to obtain, e.g., thermal behavior in the tool-chip contact and residual strains on the workpiece surface. The cBN hard turning simulations and experiments are done for powder-based $\mathrm{Cr}-\mathrm{Mo}-\mathrm{V}$ tool steel, Uddeholm Vanadis 8 using MQL subcooled to $-10{ }^{\circ} \mathrm{C}$ and regular MQL at room temperature. The cutting forces and tool wear are measured from the experiments that are used as the calibration factor for the simulations. After calibration, the simulations are used to evaluate the thermal effects of the subcooled MQL, and the surface residual strains on the workpiece. The simulations are in good agreement with the experiments in terms of chip morphology and cutting forces. The cutting experiments and simulations show that there is only a small difference between the subcooled MQL and regular MQL regarding the wear behavior, cutting forces, or process temperatures. The simulations predict substantial residual plastic strain on the workpiece surface after machining. The surface deformations are shown to have significant effect on the simulated cutting forces after the initial tool pass, an outcome that has major implications for inverse material modeling.
\end{abstract}

Keywords MQL $\cdot$ FEM $\cdot$ Cryogenic $\cdot$ Tool wear $\cdot c B N \cdot$ Sustainability

\section{Introduction}

Machining operations are among the most common manufacturing processes used in industry. Therefore, even small changes in productivity, energy efficiency, and sustainability of machining operations have major influence in the global scale. Sustainability has become increasingly an important factor in manufacturing. One of the earliest mentions of

Sampsa V.A. Laakso

sampsal@chalmers.se

1 Department of Industrial and Materials Science, Chalmers University of Technology, Hörsalsvägen 7B, 41258 Gothenburg, Sweden

2 Faculty of Technology, Department of Mechanical and Materials Engineering, University of Turku, Joukahaisenkatu 3, 20520 Turku, Finland sustainable manufacturing was in a paper by James Moore in 1977, where he envisioned the future goals of manufacturing organizations to be "less capital intensive, less energy consuming, more rewarding to workers, less demanding of raw materials and sustainable much further into the future"[1]. Since then, sustainability has become one of the focus areas of manufacturing research. Sustainability research builds upon Life Cycle Assessment (LCA), which sustainability has surpassed in publication volume at the beginning of the twenty-first century. Ong et al. (2001) [2] developed a Life Cycle Assessment tool for estimating the harmful emissions caused by material processing. Kumaran et al. (2001) [3] did similar research on environmental LCA for products. Duflou et al. (2012) [4] investigated the energy efficiency of production and their results show that there is not much that can be done in process mechanics level, but manufacturing system level optimization offers some possibilities for higher 
efficiency. Teece (2007) [5] considers the global manufacturing environment and concludes that companies aiming for sustainability require dynamic and flexible management. For more technical solutions for improved sustainability in machining, Jayal et al. (2010) investigate a sustainability index that considers the following criteria: (1) safety, health, and environment and (2) cost of machining, power consumption, and waste management. Their paper considers sustainable machining in three groups, i.e., dry machining, minimum quantity lubrication (MQL), and cryogenic machining, which all have their benefits and disadvantages [6]. Pušavec et al. (2010) analyzed LCA of different cooling strategies, flood, high-pressure cooling (HPC), and cryogenic cooling. Their results show that cryogenic cooling with liquid nitrogen has the highest potential for improved sustainability of machining superalloys [7]. Sivaiah et al. (2018) compared the machining of stainless steel with cryogenic, emulsion, and MQL cutting fluids against dry cutting conditions. Cryogenic coolant performed the best in all measured categories: cutting temperature, tool wear rate, and surface roughness. MQL was the second best option, third was flood cooling, and dry cutting was expectedly the worst [8]. A more fundamental investigation of the cooling capability of cryogenic coolants and flood emulsion is given in Pušavec et al. (2019) [9]. The tradeoff in optimization between sustainability and productivity requires more advanced predictive process models [6]. Regarding that goal, Avram et al. (2011) developed a multi-criterion optimization tool for sustainable machining. Their results show that MQL is the optimal solution for performance and sustainability [10].

In general, cutting fluids are used to improve tool life and surface quality during machining operations by reducing cutting temperature and friction. Typical cutting fluids are wateroil emulsions, with emulsifiers and additives to prevent corrosion and bacterial growth. The disposal of cutting fluids is expensive because of the toxic additives in the emulsions and the machine oils and heavy metals that are mixed with the fluids during the machining process. To improve the costefficiency and to reduce the environmental impact, the amount of cutting fluids applied need to be minimized and the toxic substances in the cutting fluids need to be removed. Both objectives can be achieved by using pure-vegetable oil with MQL delivery system. Vegetable oil is a sustainable, nontoxic, renewable, and biodegradable alternative to traditional cutting oils [11]. A comprehensive literature review by Sankaranarayanan et al. (2021) shows that bio-friendly cutting fluids are increasing their market share, which is motivated by the good lubricating properties of vegetable oils and growing environmental consciousness [12]. Khan et al. (2020) evaluated multiple cooling strategies on their case examples, regarding productivity and sustainability aspects. They used flood, MQL, and hybrid CryoMQL (HCM) coolants and calculated the energy consumption while machining titanium alloys, and the results show that the HCM method has the lowest sustainability impact and highest productivity [13]. Sudheer et al. (2014) investigated compressed refrigerated air, dry and Propylene Glycol MQL cooling mediums in a cutting of metal matrix composite (MMC) materials. Their results show that compressed refrigerated air improves the surface roughness slightly compared with dry cutting conditions and propylene glycol has significant effect by reducing the surface roughness by $50 \%$ compared with other mediums in the study [14]. It has also been shown that using MQL decreases the tool-chip contact length [15] and leads to reduced tool wear, cutting forces, and surface roughness, but the poor cooling effect is the major disadvantage of MQL [16]. On the other hand, in some cases, the lower cooling effect can be beneficial with regard to tool wear, for example in drilling, where the center of the tool has a higher wear rate with emulsion than with MQL [17]. The cooling effect of the MQL can be increased by using MQL combined with liquid $\mathrm{N}_{2}$ or $\mathrm{CO}_{2}$, but these systems have a high initial cost. Khanna et al. (2021) review different cryogenic setups like hybrid cryo-MQL and high-pressure cutting fluids, etc. They conclude that the field is yet matured enough to give specific guidelines for selecting a cooling method for each case but investing in the development of cryogenic technologies is necessary for sustainable and economical machining [18]. A new and alternative approach is to use liquid $\mathrm{N}_{2}$ in a heat exchanger to cool the MQL oil to subzero temperatures. This paper investigates a subcooled vegetable-oil MQL system patented by Accu-Svenska Ab [19] in hard machining of Vanadis 8 tool steel using 3D FEM simulations and experiments to compare the machining performance between MQL and subcooled MQL at $-10{ }^{\circ} \mathrm{C}$. Cryogenic temperature has been defined to be below $-150{ }^{\circ} \mathrm{C}$ by National Institute of Standards and Technology [20]. Therefore, this paper refers to the Accu-Svenska system as subcooled MQL and other cryogenic MQL systems as CryoMQL. There have not been previous studies on machinability of Vanadis 8 , and there are only very few papers investigating the Accu-Svenska CryoMQL system. In addition, the simulation methodology in this paper shows that using the approach proposed in this paper leads to better results than previously reported.

\section{Literature review}

The existing research in cryogenic coolants is focused on a machining of aerospace alloys like Ti-6Al-4V and Inconel 718 , but some other work materials have also been investigated like tool grade aluminum and steel. Shokrani et al. (2017) investigated a machining of Inconel 718 using MQL, $\mathrm{LN}_{2}$, and CryoMQL cooling strategies. The results show that CryoMQL is superior in terms of tool life and surface roughness compared with MQL or $\mathrm{LN}_{2}$. $\mathrm{LN}_{2}$ alone showed $18 \%$ 
improvement in surface roughness and doubled tool life [21]. Y1ldırım et al. (2020) compared different cutting fluids ( $\mathrm{LN}_{2}$, MQL, and CryoMQL) in the machining of Inconel 625. The results show contradictory results to Shokrani et al. (2017), because their results show that $\mathrm{LN}_{2}$ leads to highest tool wear and surface roughness but CryoMQL on the other hand leads to lowest tool wear and surface roughness. Adhesive wear was identified as the principal wear mechanism in all cooling conditions. The most pronounced chip serration was observed in cryogenic cutting conditions [22]. Interesting new approach was investigated by Olsson et al. (2021), where a $\mathrm{LN}_{2}$-cooling and induction heating was applied to a machining of pure tungsten and pure niobium. It was found that $\mathrm{LN}_{2}$ and hybrid $\mathrm{LN}_{2}$ with induction performed the best for machining the tungsten, but the conventional high-pressure coolant was optimal for machining niobium [23]. In this paper, the state-ofthe-art simulation practices of modeling cryogenic and subcooled cutting fluids are mapped in order to model the subcooled MQL investigated in this paper. In addition, publications investigating friction and wear models are reviewed to establish a method for modeling the lubricating effect of MQL in cutting conditions. Most of the simulations in the literature are done with Deform, AdvantEdge, or Abaqus using a high heat transfer coefficient between the tool and environment and workpiece and environment. In some cases, the cooling effect has also been simulated using CFD. All papers investigating tool wear used Usui's wear model. The modeling of friction in metal cutting is typically done in dry conditions, but in this paper, the focus is on MQL where the friction is in pure-oil environment. Many papers report an increasing friction coefficient with increasing cutting speed (sliding speed), which is opposite behavior from what is commonly observed in dry cutting conditions.

\subsection{Simulating cryogenic cutting fluids and MQL}

Salame et al. (2019) simulated 2D orthogonal a cutting of Ti6Al-4V using FEM model in Abaqus and use the cutting simulation temperature distributions as input to CFD model of cryogenic cooling (direct application of liquid $\mathrm{CO}_{2}$ ) in Ansys. Their results show that cryogenic nozzle placement has significant effect on the cutting temperature and the position of the maximum temperature, somewhat counterintuitively so that farther nozzle position (4-mm vs. $8-\mathrm{mm}$ distance) led to lower temperature and the maximum temperature moved from the secondary to the primary shear zone [24]. Pereira et al. (2017) investigated cryogenic MQL nozzle technology with CFD simulations, showing optimal design for mixing $\mathrm{CO}_{2}$ with microdroplets of MQL oil in the nozzle. The CryoMQL reached $93.5 \%$ tool life compared with the flood cooling while milling Inconel 718 [25]. Hribersek et al. (2017) determined the heat transfer coefficient for $\mathrm{LN}_{2}$-cooled Inconel 718 using inverse simulations. The simulations show that the heat transfer coefficient is strongly dependent on the temperature difference between the surface and gas, being $75 \mathrm{~kW} / \mathrm{m}^{2} \mathrm{~K}$ at $200{ }^{\circ} \mathrm{C}$ temperature difference and reducing exponentially; $\Delta \mathrm{T}=160^{\circ} \mathrm{C}, \mathrm{h}=15 \mathrm{~kW} / \mathrm{m}^{2} \mathrm{~K}$, and about $1.5 \mathrm{~kW} / \mathrm{m}^{2} \mathrm{~K}$ at temperature difference below $50{ }^{\circ} \mathrm{C}$ [26].

Sun et al. (2015) investigated a machining of Ti-5553 alloy with MQL, flood, and cryogenic cooling using experiments and FEM simulations with Deform 2D. Cryogenic cooling was simulated using an additional heat exchange window under the tool flank, with environment temperature of $-184{ }^{\circ} \mathrm{C}$ and convection coefficient of $10000 \mathrm{~kW} /\left(\mathrm{m}^{2} \mathrm{~K}\right)$. The FEM simulations are in good agreement with experiments done using cryogenic cooling. Cryogenic cooling reduced cutting forces by $30 \%$ compared with flood and MQL [27]. Kaynak et al. (2018) followed the work of Sun et al. (2015) closely, but with more experimental data, more reliable thermal imaging, and more detailed descriptions of the simulations. The simulations are relatively accurate in comparison to experiments with 10-30\% error with respect to cutting forces, temperature, and chip morphology. $\mathrm{CO}_{2}$ coolant reduces cutting temperature by $15-52 \%$ compared with dry cutting [28]. Imbrogno et al. (2017) simulated Ti-6Al-4V cutting using Deform 3D and TANH model. $\mathrm{LN}_{2}$ cryogenic cooling was simulated using local heat transfer windows with $-196{ }^{\circ} \mathrm{C}$ temperature and heat convection calculated by method implemented by Umbrello [29] and proposed by Astakhov [30]. The results show good agreement with experiments regarding cutting force and temperature and less so for feed force [31]. Davoudinejad et al. (2015) simulated cryogenic cooling of an orthogonal cutting using Third Wave Systems AdvantEdge FEM software. The heat transfer coefficient was calibrated to $2000 \mathrm{~kW} / \mathrm{m}^{2} \mathrm{~K}$ by testing with pre-selected values between 46.75 and $5000 \mathrm{~kW} / \mathrm{m}^{2} \mathrm{~K}$. Simulations were first verified using dry machining conditions, which were in good comparison with the experiments having error less than $10 \%$ in all control variables: cutting forces, feed forces, and chip thickness. The simulations with cryogenic conditions also produced low error. The simulations and experiments show that the cutting forces and stresses are higher with cryogenic cooling than with dry cutting while chip thickness and serration frequency reduced with cryogenic cooling [32]. Mishra et al. (2019) simulated a machining of Ti-6Al-4V with a textured tool in cryogenic cooling conditions using AdvantEdge FEM software. The simulations show that realistic cutting temperature was achieved using $3000 \mathrm{~kW} / \mathrm{m}^{2} \mathrm{~K}$ heat convection coefficient at tool-chip interface. Overall accuracy of the simulations was not optimal [33]. Dix et al. (2014) modeled drilling assisted with $\mathrm{LN}_{2}$ cryogenic coolant. Drill with internal coolant channels was simulated with Deform 3D. The heat transfer coefficients used in the simulations varied by work temperature $23.3 \mathrm{~kW} / \mathrm{m}^{2} \mathrm{~K}$ for $-181{ }^{\circ} \mathrm{C}$ and $46.8 \mathrm{~kW} / \mathrm{m}^{2} \mathrm{~K}$ for $650{ }^{\circ} \mathrm{C}$, while ambient temperature was set to $-191^{\circ} \mathrm{C}$. The 
simulations showed good agreement with the experiments [34]. Rotella et al. (2014) investigate a machining of aluminum AA7075-T651 with cryogenic cutting fluid using experiments and simulations. Dry conditions lead to higher cutting forces and lower workpiece hardness, which is credited to reduced thermal softening and grain growth during cryogenic cooling. The simulations are done with Deform 3D using 20 $\mathrm{W} / \mathrm{m}^{2} \mathrm{~K}$ heat convection coefficient between the tool and environment and workpiece and environment. The tool-chipinterface heat conduction was set to $55000 \mathrm{~kW} / \mathrm{m}^{2} \mathrm{~K}$ to enable reaching the thermal steady state quickly. A modified Johnson-Cook model was used for the flow stress modeling with room temperature set to $-182{ }^{\circ} \mathrm{C}$. The Johnson-Cook model was modified by replacing the yield strength equivalent parameter with Hall-Petch relation, which is explained in Farrokh and Khan (2009) [35]. Model parameters were taken from Curle and Govender (2010) [36]. Cryogenic cooling effect was simulated using a local heat transfer window with the convection coefficient initially set to $0.2 \mathrm{~kW} / \mathrm{m}^{2} \mathrm{~K}$, and the grain size was predicted using Zener-Hollomon equation. Simulations predicted cutting force components with decent accuracy and grain size and hardness with relatively good accuracy [37]. Yu Su (2015) investigated cryogenic MQL in a machining of AISI H13 steel using 3D FEM simulations. The MQL was assisted with refrigerated compressed air (RCA) at different temperatures $\left[-10^{\circ} \mathrm{C} ;-140{ }^{\circ} \mathrm{C}\right]$. The simulations were done with Deform 3D using the Johnson-Cook flow stress model and a local heat transfer window for the cryogenic effect. The heat transfer coefficient was 100 $\mathrm{W} / \mathrm{m}^{2} \mathrm{~K}$. The results show that the optimal RCA temperature was dependent on cutting speed and was $-30^{\circ} \mathrm{C}$ for $47 \mathrm{~m} / \mathrm{min}$ and $-50{ }^{\circ} \mathrm{C}$ for $104 \mathrm{~m} / \mathrm{min}$. Cutting temperature and cutting forces were decreased significantly while using the RCA aided MQL. The accuracy of the simulations was not adequately evaluated [38]. Shi et al. (2019) used a hybrid CFD and FEM approach to simulate $\mathrm{LN}_{2}$ cryogenic cooling in the machining of Ti6Al4V titanium. They use a Voce power law for flow stress modeling because the Johnson-Cook model gives invalid values below the reference temperature. They used a CFD to determine the convection coefficient between the $\mathrm{LN}_{2}$ spray and the tool/workpiece, which was estimated in range from 24 to $50 \mathrm{~kW} / \mathrm{m}^{2} \mathrm{~K}$. Their simulation results were in relatively good comparison with the experiments: $7 \%$ error regarding the chip temperature and $10-24 \%$ error in the cutting force components. They explain the high force error with a ploughing effect in the feed direction, friction model errors, and unaccounted tool wear [39].

Hard machining has some special characteristics that arise from the geometry and material properties of the workpiece: the cutting depth and feed are small; therefore, the effect of friction and work material residual strains has higher effect than in cutting with larger chip volume. The strain hardening behavior of hardened materials is steeper, and regular
Johnson-Cook model is not optimal for capturing the shape of the strain hardening curve. The cutting force proportions are different from regular cutting, since the perpendicular or passive force becomes the largest cutting force component in hard machining, instead of the main cutting force. The temperature of the workpiece does not increase much since most of the heat is removed with the chip, and the heat generated at the tertiary deformation zone is small compared to the volume of the workpiece because of the small chip volume. In existing literature, there are only few publications on FEM modeling of hard machining. One such work is done by Umbrello et al. (2008), where they developed a flow stress model for AISI $\mathrm{H} 13$ based on the J-C model with hardness dependency. The model includes additional terms in the strain hardening equations, to take into account the hardness variations in the work material. The model gives relatively accurate $(<10 \%$ error $)$ simulation results regarding cutting forces and chip morphology in four cases of machining AISI H13 at different hardness (28-52 HRC). Only the feed forces were overestimated by $11-16 \%$ in all cases. The simulations were done with STFC Deform [40]. Much of the data and methods used in Umbrello et al. (2008) were inspired by Yan et al. (2007) [41]. Saez-deBuruaga et al. (2019) present a flow stress model for hard machining of $42 \mathrm{CrMoS} 4$. Their work illustrates well the steep strain hardening and leveling of the flow stress in hardened steels, and why J-C model is not optimal for fitting such behavior. Their model is based on yield stress and saturation stress and filling the gap between with exponential relation. The model fits well to the presented data; however, the simulated cutting forces have $10 \%$ average error and contact lengths $29 \%$ average error [42]. To illustrate the poor applicability of Johnson-Cook model to strain hardening behavior of hardened steels, the Saez-de-Buruaga model and the best fit of Johnson-Cook model to the same data set are shown in Figure 1. To overcome this issue in this paper, the flow stress is modeled using tabular data.

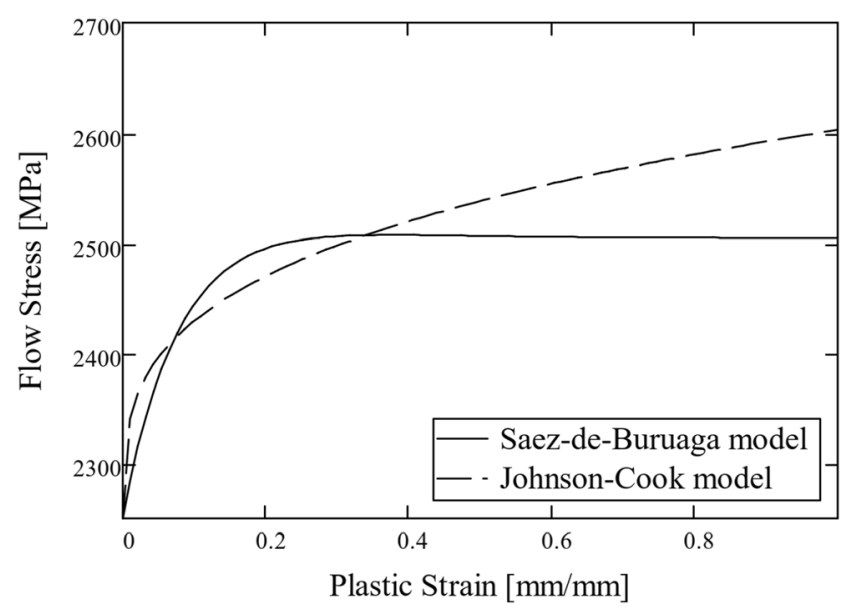

Figure 1 Comparison of Saez-de-Buruaga model and Johnson-Cook model for hardened $42 \mathrm{CrMoS} 4$ steel 


\subsection{Tool wear}

Yadav et al. (2015) simulated MRR (material removal rate) and flank wear in a dry turning of Inconel 718, using Deform 3D. They used somewhat an unorthodox approach with an unusually long workpiece model with a coarse mesh, whereas it is more common to use exaggerated wear model parameters to simulate longer cutting distance. The simulations were built with the Johnson-Cook flow stress model, a Coulomb friction, and Usui's wear model. The simulations show good agreement $(<7 \%)$ with experiment regarding MRR and flank wear, but the paper does not report the cutting forces, so the simulation accuracy might be specific to MRR and flank wear in the local cutting conditions used [43]. Binder et al. (2015, 2017) used Deform 3D and Usui's wear model to simulate an in situ tool wear by updating the tool geometry while machining AISI 1045 with coated and uncoated carbide tools. The results show good agreement with the experimental tool wear, but the paper does not compare the chip morphology or the cutting forces [44, 45]. Schulze and Zanger (2011) simulated tool wear in 2D orthogonal a machining of Ti-6Al-4V using Abaqus and Usui's wear model. The WC tool was modeled rigid and the contact between the tool and workpiece was modeled with Coulomb friction. Ti-6Al-4V was modeled with Johnson-Cook flow stress model J-C failure model. The results show good comparison with experimental tool wear and reasonably good comparison with specific cutting force and chip temperature, both being within $\pm 15 \%$ [46]. Yen et al. (2004) developed a wear simulation with Deform 2D and Konti-Cut user script that updates the tool geometry based on the Usui's wear model. Work material is AISI 1045 and tool is uncoated carbide. Their results showed that the adopted wear model was not able to capture wear at the tool edge, i.e., flank wear, but the wear was concentrated on the rake face near the end of tool-chip contact length [47]: "Besides, it is known that high wear rates are normally seen at the initial stage of a cut for a sharp edge due to the weaker edge strength and possible micro-chipping." Laakso et al. (2017) showed that the plastic deformation and creep at the tool edge contribute to the high initial wear rate [48] and the initial wear was shown to contribute a major proportion of the feed force in [49], and the same conclusion was made later in Peng et al. (2019) [50]. In order to circumvent the issue with flank wear not progressing as fast as the wear at rake face, Yen et al. set a $60-\mu \mathrm{m}$ initial flank wear land with $3^{\circ}$ inclination and repeated the simulation. This simulation showed defined flank wear progression over time, the $V_{\mathrm{B}}$ growing to $120 \mu \mathrm{m}$ in $6 \mathrm{~min}$. The paper did not report any validation of cutting forces or chip morphology. Tamizharasan et al. (2012) optimized tool geometry regarding tool wear in a machining of AISI 1045 using Deform 3D with Usui's wear model and analysis of variance to investigate the effect of geometry parameters. Their results did not reflect the reality of experiments with average cutting force error of $82 \%$, and the wear depth from simulations was $10^{-4} \mathrm{~mm}$ and $0.537 \mathrm{~mm}$ in experiments [51]. Szczotkarz et al. (2021) investigate tool wear in machining of 316L stainless steel with MQL and dry cutting conditions. Their results show that MQL reduced tool wear by $18 \%$ compared to dry cutting. Their results also show that MQL can very well reduce adhesive wear, but for example notch wear is not significantly affected by MQL compared to dry conditions [52].

\subsection{Friction and lubrication}

Metal cutting is typically modeled in dry cutting conditions for simplicity and much of the research work is focused on modeling the friction in dry conditions. In dry cutting conditions, friction is shown to reduce with increased cutting speeds, shown in, e.g., Mane et al. (2020) [53]. This paper investigates cutting with MQL and subcooled MQL, and therefore, the friction is modeled in lubricated environment, in which the behavior of friction is significantly different from dry condition. Claudin et al. (2010) investigate the effect of oil on friction at tool-workpiece interface. They provide insightful review on friction and lubrication in metal cutting, bringing the controversial issues to discussion: (1) if cutting lubricant can penetrate the tool-chip interface because of the high contact pressure, (2) are tribological tests like pin-on-disc method representative to metal cutting conditions, and (3) different approaches for friction testing developed specifically for metal cutting. The authors present a tribometer that they use to test friction in dry and oil-lubricated machining conditions for AISI 4140 workpiece and TiN-coated carbide tool. The results of the tribometer test show an exponentially decreasing friction coefficient $\mu \in[0.6 ; 0.2]$ with increasing sliding velocity for dry condition and the static friction $\mu \approx 0.1$ in lubricated conditions. Their results also show that oil does indeed penetrate the contact interface even at very high $\sim 2.5$ GPa contact pressures, objecting the notion, e.g., in [54]. The oil needs to be continuously reapplied since it stays in the interface only for a short time $(\sim 1 \mathrm{~s})$ varying with sliding speed. Adding oil to a dry condition starts to affect the contact after 0.2 to $0.6 \mathrm{~s}$ [55]. Pottirayil et al. (2010) experimented with paraffinic, naphthenic, and aromatic oil in metal cutting, using a tribometer with the cutting tool and a friction pin submerged in oil. Their results show a steady friction coefficient of 0.1 and peak friction increasing between 0.2 and 0.6 with increasing sliding speed $(0.15-0.38 \mathrm{~m} / \mathrm{s})$. They conclude that friction testing for metal cutting must be done by in situ experiment; otherwise, the environmental contamination and oxidation will affect the results [56]. Cassin and Boothroyd investigated lubrication in a machining of copper, where they observed a clear increase in the friction angle with increasing cutting speed while using various cutting fluids and constant friction angle with dry cutting [57]. Campen et al. (2012) 
dedicated their research efforts on investigating the increase of lubricated friction with increasing sliding speed. Their paper scope is limited to organic lubricants in AISI 512100 ball-disc contact. Their results show that the friction coefficient is small $<0.18$ in all cases, and a typical trend is increasing friction with increasing sliding speed $\in\left[10^{-7}\right.$ to $\left.10^{-2} \mathrm{~m} / \mathrm{s}\right]$. Their conclusions suggest that the small friction at low sliding speed that increases with speed is caused by molecular behavior of the oils: sliding between ordered close-packed monolayers [58]. Faverjon et al. (2013) investigate the friction of HSS, WC, and PCD pins in a sliding contact with 324.0 aluminum in dry and straight oil MQL conditions. The tribometer results show that all experiments in dry condition lead to a decrease of the friction coefficient with increasing speed, and a steady or increasing friction coefficient in MQL-lubricated conditions. The sliding speeds varied between 20 and $1500 \mathrm{~m} / \mathrm{min}$ where the friction is between 1 and 0.2 in dry conditions and around 0.1 and 0.2 in lubricated conditions [59]. Kaynak et al. (2018) compare MQL, flood, and HPC in a machining of Ti5553. Apparent friction coefficient can be calculated $\left(\mu=F_{f}\right.$ $F_{C}$ ) from their cutting force measurements, showing a clear trend of increasing friction with increasing cutting speed for all lubrication conditions [60]. In addition to the sliding speed, the surface finish and the contact temperature are found to affect the friction coefficient [61].

\section{Materials and methods}

The subcooled MQL is evaluated using cutting experiments and simulations. The work material is Vanadis 8, the tool is a $\mathrm{cBN}$ insert, and the cutting experiments are done with a lathe. The simulations are done with Deform 3D FEM software.

\subsection{Cutting experiments}

The cutting experiments were done using an EMCO Turn 365 CNC lathe with Kistler 9275 force measurement system and Accu-Svenska's prototype subcooled MQL system. The cooling and lubrication are delivered only at the rake face, in front of the tool-chip interface. The coolant nozzle placement is shown in Figure 2. Tool wear was measured in 50-mm cutting length intervals with Zeiss Discovery V20 optical microscope and with FEI/Philipps XL-30 SEM. The work material is a powder-based tool steel from Uddeholm, commercially named as Vanadis 8 . The alloying elements of Vanadis

Table 1 The chemical composition of Vanadis 8, wt $\%$

\begin{tabular}{llllll}
\hline $\mathrm{C}$ & $\mathrm{Si}$ & $\mathrm{Mn}$ & $\mathrm{Cr}$ & $\mathrm{Mo}$ & $\mathrm{V}$ \\
\hline 2.3 & 0.4 & 0.4 & 4.8 & 3.6 & 8 \\
\hline
\end{tabular}

8 are presented in Table 1. The material is machined in hardened state at $\sim 62-64$ HRC. Sandvik cBN 7125 grade insert was used for all experiments. The cutting parameters were selected based on Sandvik recommendations and initial cutting tests. The cutting parameters are cutting speed $\mathrm{v}_{\mathrm{c}} \in$ $[50,75,100 \mathrm{~m} / \mathrm{min}]$, cutting feed $f=0.15 \mathrm{~mm} / \mathrm{rev}$, and cutting depth $a_{\mathrm{p}}=0.15 \mathrm{~mm}$. The experiments were done with MQL and subcooled MQL that are compared with simulated results. The experimental work done parallel to this paper shows that the -10 degrees is the optimal temperature for this AccuSvenska Cryo MQL setup. Going below -10 degrees does not improve the tool wear. Tool wear is visualized using Logit model (Eq. 1) that is capable of capturing the wear progression over time, instead of only the flank wear length $V_{\mathrm{B}}$ at the end of tool life. Logit model is described in detail by Laakso and Johansson (2019) [62]. In this paper, the $t_{\max }$ is solved from Taylor's tool life Eq. 2 [63].

Logit model, where the parameters $a, b$, and $m$ are for calibrating the wear progression shape

$$
\begin{gathered}
V B(t)=a+h\left(\frac{t}{t_{\max }}\right)^{b}\left(V B_{\max }-a\right) \\
h(x)=\frac{g(x)}{g(1-m)} \\
g(x)=f(x)-f(m) \\
f(x)=\log \frac{x}{1-x}
\end{gathered}
$$

Taylor's model, where $n$ is the wear rate exponent and $C$ is the wear coefficient

$v_{c} \cdot T^{n}=C$

\subsection{Simulations}

FEM simulation have been used in metal cutting research intensively for nearly half a century. Alternative methods have been proposed like BEM, PFEM, or analytical models like one proposed by Lazoglu and Islam (2012) [64]. The simulations in this paper are done with Deform 3D that is a FEM solver based on Lagrange formulation and implicit time integration. The simulation setup is presented in Fig. 3. Time step for the simulations is $1 \times 10^{-6} \mathrm{~s}$, the element size is shown in Figure 4 for the workpiece and in Figure 5 for the tool, and the workpiece is meshed with an adaptive remeshing to avoid excessive element distortions. The tool is modeled as elastic and workpiece is elastic plastic. The simulations run for two consecutive cutting revolutions to capture the effect of the previously deformed workpiece layer on the cutting mechanics and possible temperature buildup in the workpiece. The effect of the previously deformed workpiece surface has been 
Figure 2 Cutting experiment setup with coolant nozzle

\begin{tabular}{|l|l|l|l|l|l|}
\hline $\mathrm{C}$ & $\mathrm{Si}$ & $\mathrm{Mn}$ & $\mathrm{Cr}$ & $\mathrm{Mo}$ & $\mathrm{V}$ \\
\hline 2.3 & 0.4 & 0.4 & 4.8 & 3.6 & 8 \\
\hline
\end{tabular}

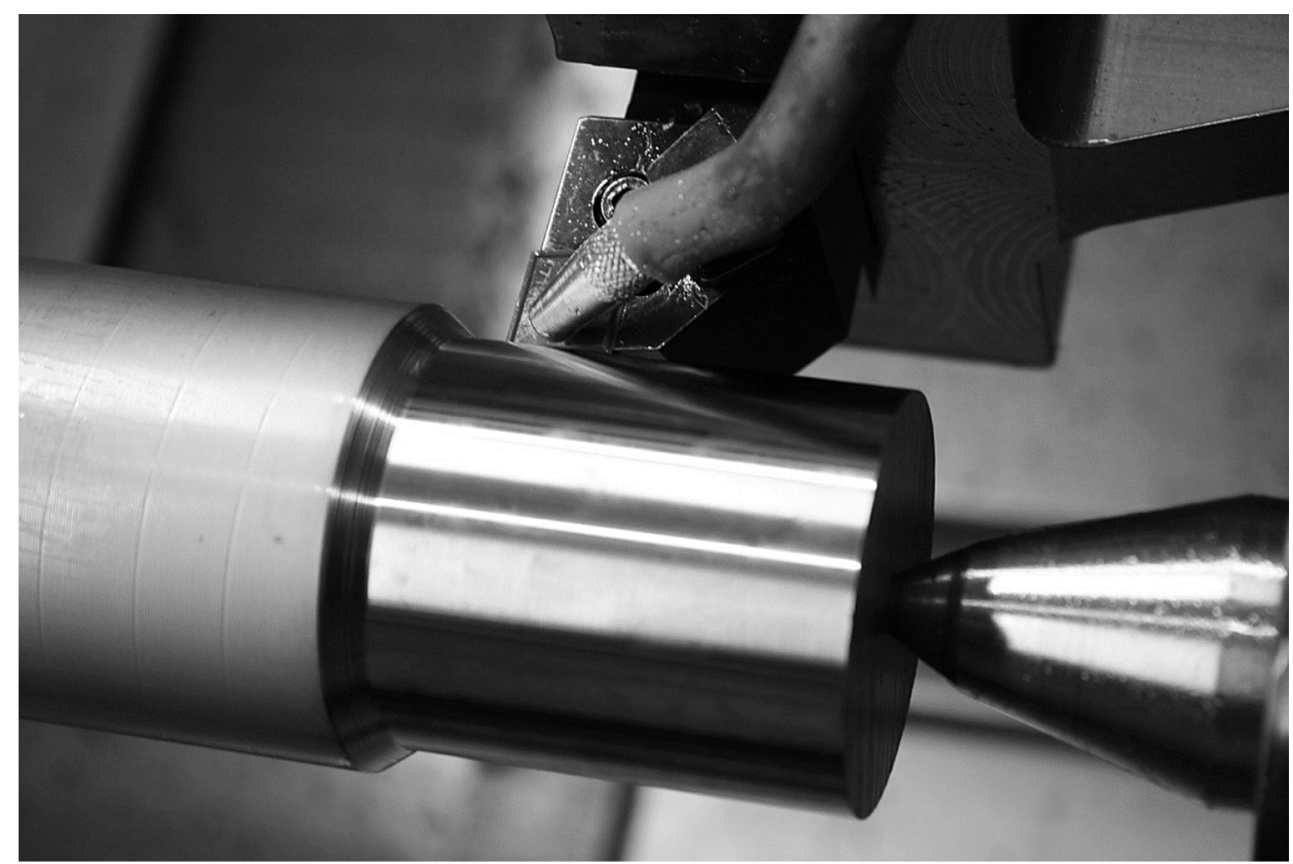

shown to affect the flow stress of the work material significantly in Laakso (2020) [65].

\subsubsection{Tool geometry}

The tool was modeled with Creo Parametric 6.0.2.0 using the insert geometry values provided by Sandvik and microscope

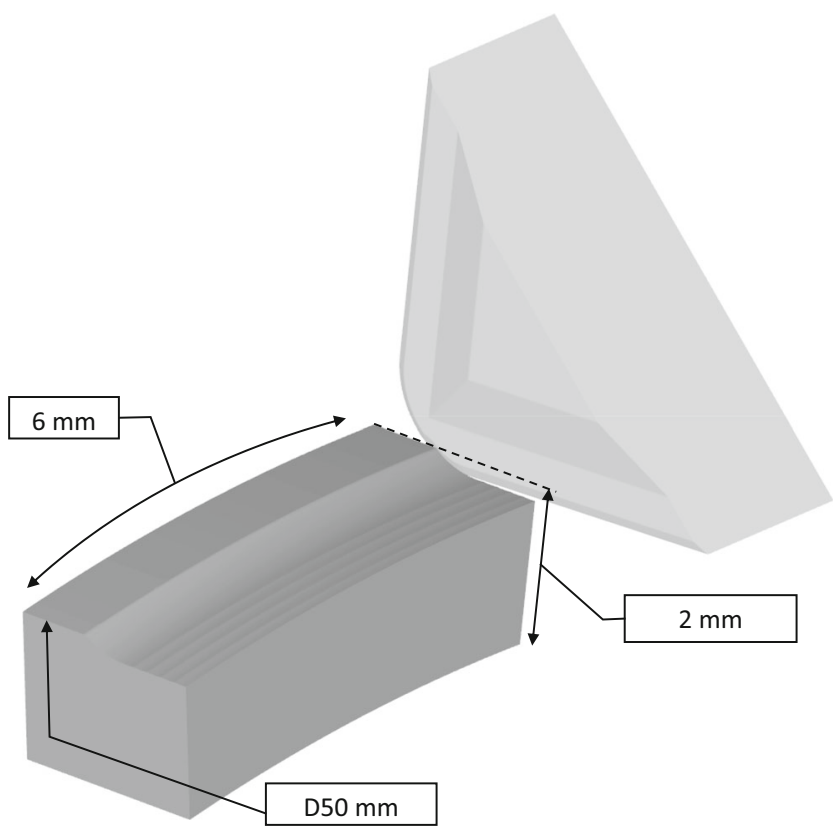

Figure 3 Simulation setup measurements. The chosen strategy of modeling the tool wear in advance was inspired by the existing research on the progressive modeling of the tool wear, which has been shown to be not ideally accurate and unproductive regarding the CPU hours. By modeling the tool wear in advance, based on the wear geometry obtained from the experiments, the error of inaccurate tool wear prediction in simulations is minimized and the simulation solving time is faster. The modeled tool geometry and mesh are shown in Figure 5. The tool was modeled with wear geometry obtained from experiments at $80-\mu \mathrm{m}$ flank wear and corresponding crater wear, shown in Figure 6.

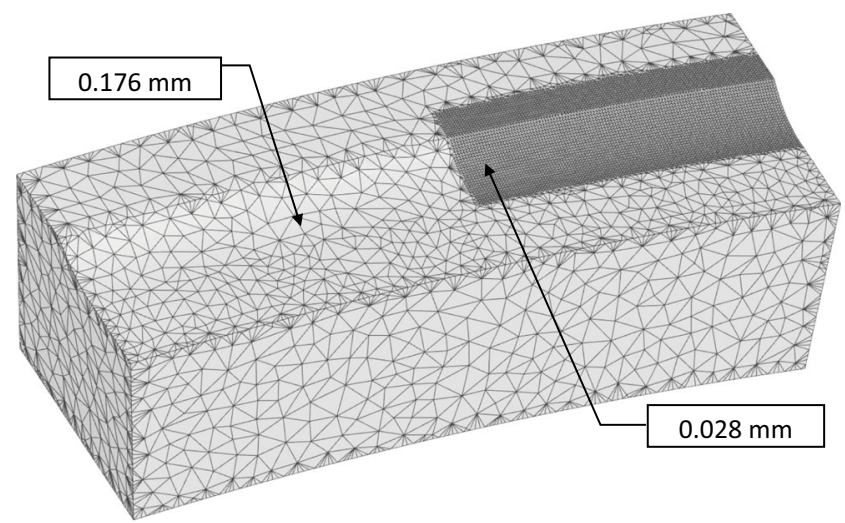

Figure 4 Workpiece mesh 


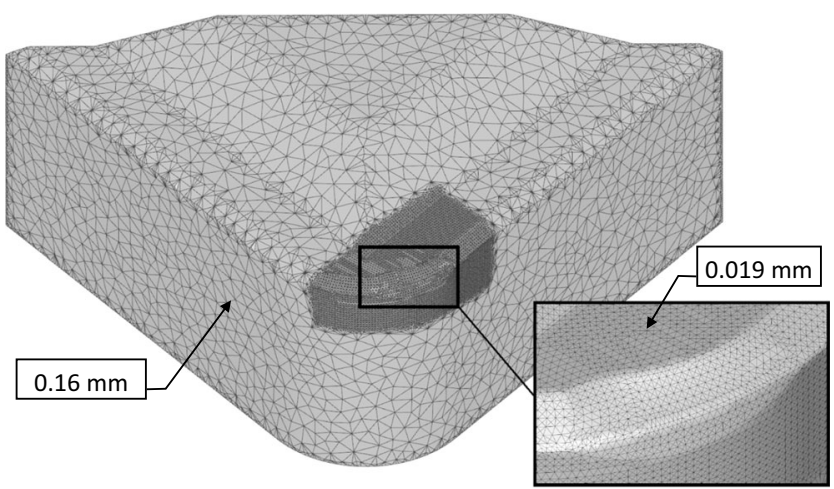

Figure 5 Tool mesh

\subsubsection{Friction}

Friction in the simulations was used between the tool and the workpiece. The friction model is shear friction, presented in Eq. 3, where $k$ is the shear yield stress and $m$ is the shear friction coefficient. The shear friction coefficients at different cutting speeds were determined using inverse analysis (presented in Section 3.3) and initial assumption based on the literature review suggesting that friction increases with increasing sliding speed in lubricated contact conditions. The determined shear friction coefficients were found to concede with the velocity dependent behavior found in literature review, as shown in Figure 7.

Shear friction model, where $\tau_{\mathrm{f}}$ is the shear friction

$\tau_{f}=m k$

\subsubsection{Heat transfer}

Heat transfer was modeled between the workpiece and the tool, between the tool and the environment, between the workpiece and the environment, between the tool and the MQL spray, and between the workpiece and the MQL spray. The heat transfer between the workpiece and the tool is modeled as a constant heat transfer coefficient of $40 \mathrm{~kW} / \mathrm{m}^{2} \mathrm{~K}$, which is commonly used in FEM studies on tool-chip interface. The convection coefficient from tool and workpiece to environment is $20 \mathrm{~W} / \mathrm{m}^{2} \mathrm{~K}$. The convection coefficient from the tool and the workpiece to a constant $-10^{\circ} \mathrm{C}$ subcooled MQL spray is $10 \mathrm{~kW} / \mathrm{m}^{2} \mathrm{~K}$, which is in line with Hribersek et al. (2017) and Shi et al. (2019) considering that the coolant in this research is not $\mathrm{LN}_{2}$ but subcooled vegetable oil [26, 39]. The subcooled MQL spray was modeled using an environmental window shown in Figure 8 that follows the tool. The subcooled MQL spray for the workpiece was similarly defined with an environmental window, shown in Figure 9.
Figure 6 The tool wear profile observed at $80-\mu \mathrm{m}$ flank length

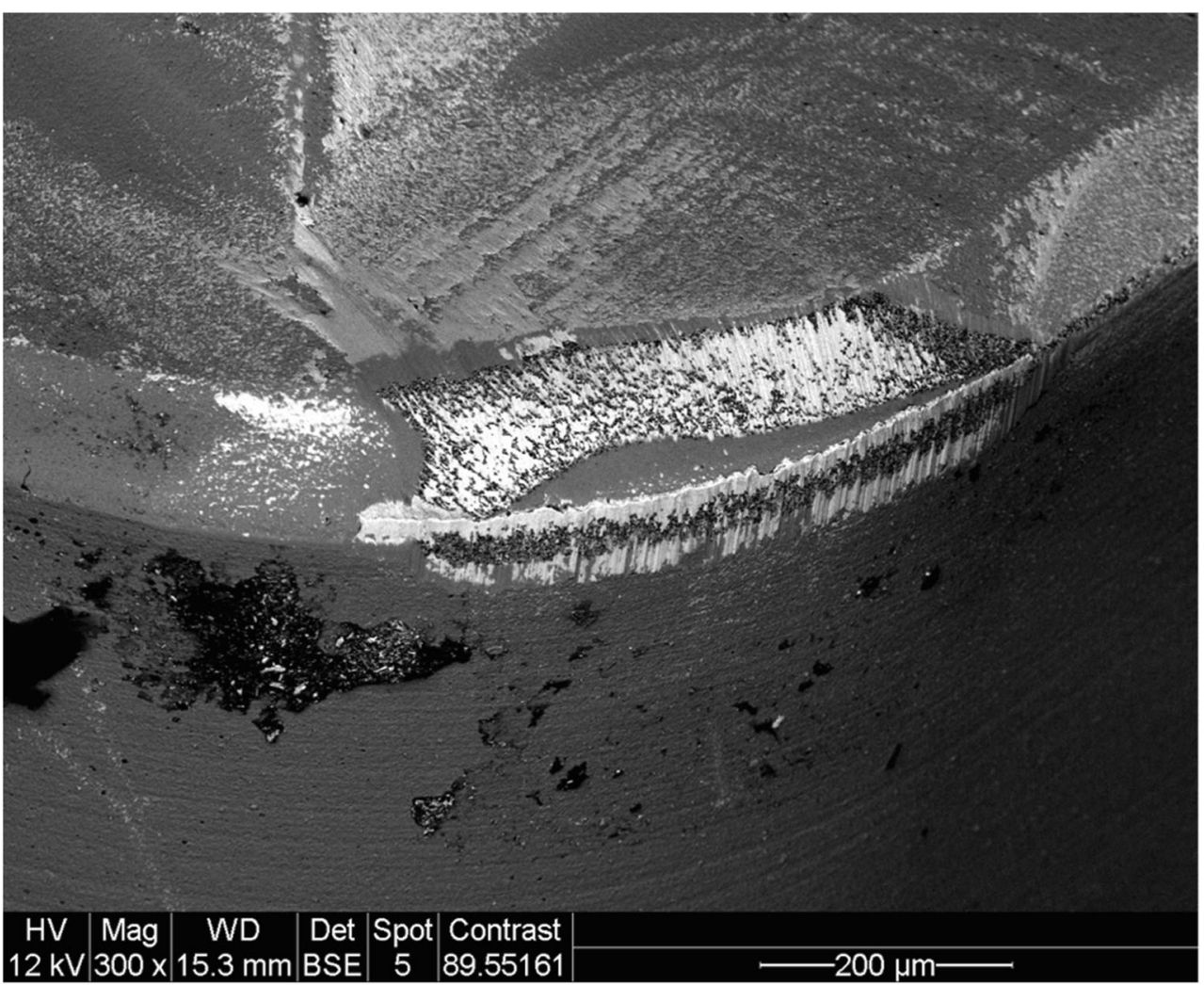


Figure 7 Shear friction coefficients at different cutting speeds

\begin{tabular}{|l|l|l|}
\hline $\begin{array}{l}\text { Shear Friction Model, } \\
\text { where } \tau_{f} \text { is the shear } \\
\text { friction }\end{array}$ & $\tau_{f}=m k$ & 3 \\
\hline
\end{tabular}

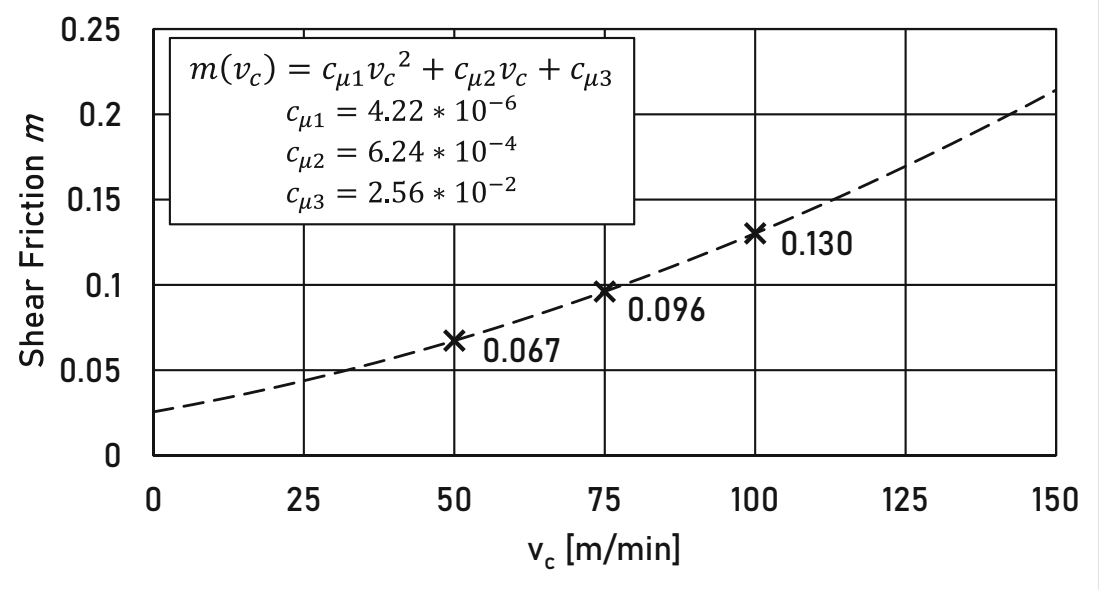

\subsubsection{Mechanical properties of $\mathrm{CBN}$}

Agmell et al. presents temperature-dependent material properties for Seco Tools cBN170 [66]. Thepsonthi and Özel simulate $\mathrm{cBN}$ coating with Deform 2D using isothermal material properties for the coating [67]. Solozhenko et al. (2019) determine the physical properties of nanocrystalline cBN, showing a significant increase in strength and hardness compared with generic $\mathrm{cBN}$ [68]. Li et al. investigate the properties of $\mathrm{SiC}$ whisker reinforced cBN. Adding $20 \mathrm{wt} \%$ of $\mathrm{SiC}$ whiskers increased flexural strength with $40 \%$, Vickers hardness with $30 \%$, and fracture toughness with

Figure 8 Subcooled MQL spray defined with environmental window for the tool

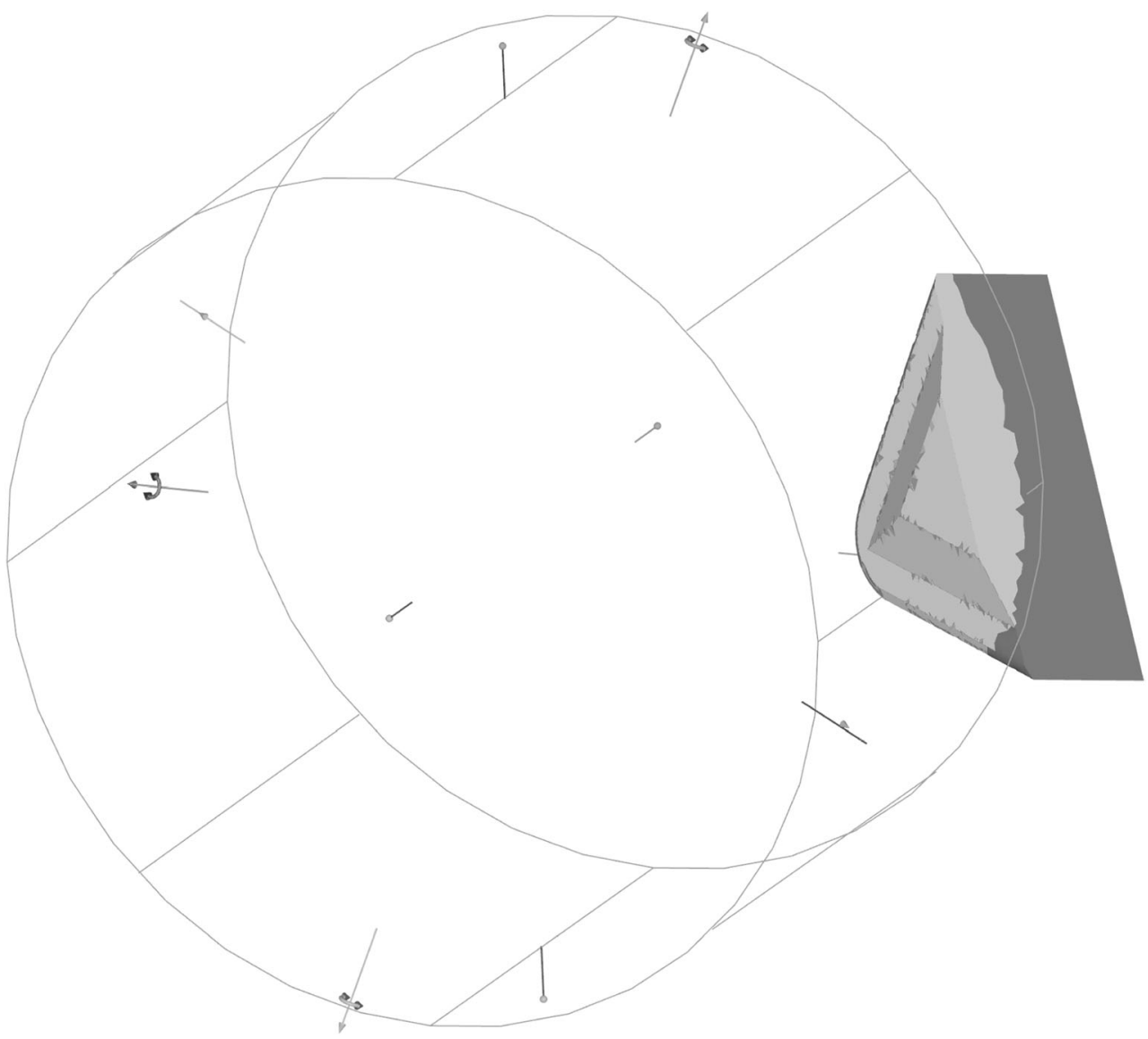


Figure 9 Subcooled MQL spray defined with environmental window for the workpiece

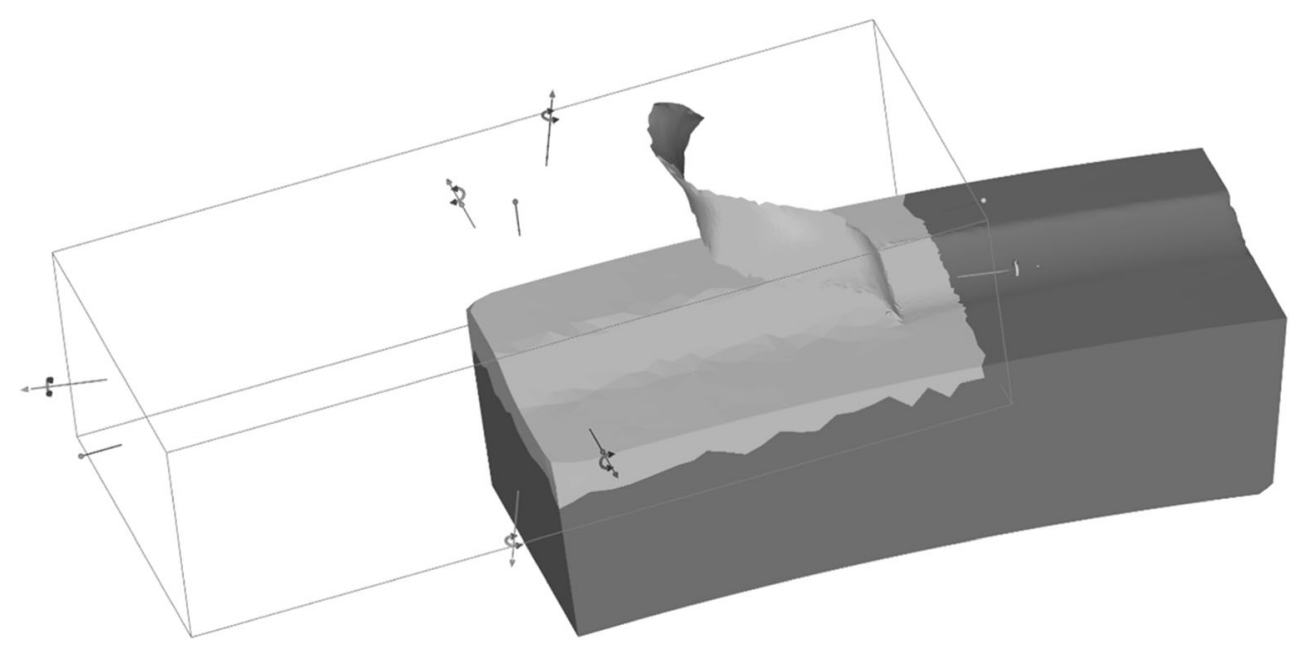

$20 \%$ [69]. The values used in this paper for the Sandvik cBN grade 7125 are $E=652 \mathrm{GPa}, v=0.27$, thermal expansion $5.2 \times 10^{-6} \mathrm{~m} / \mathrm{mK}$, thermal conductivity $100 \mathrm{~W} / \mathrm{mK}$, and specific heat $3.26 \mathrm{~N} / \mathrm{mm}^{2} /{ }^{\circ} \mathrm{C}$. The same values are used in Thepsonthi and Özel (2011) [70].

\subsubsection{Mechanical properties of Vanadis 8}

Mechanical properties of Vanadis 8 hardened to $62.9 \mathrm{HRC}$ are modeled using tabular flow stress data that was compiled from tensile testing data provided by Uddeholm, shown in Table 2, a thermal softening curve determined from temperaturedependent modulus of elasticity data calibrated with inverse methods and a rate hardening multiplier from the JohnsonCook model that was calibrated with an inverse method. The flow stress strain dependency is shown in Figure 10, thermal softening is shown in Figure 11, and the Johnson-Cook rate hardening in Eq. 4. The rate hardening parameters are $2.39 \times 10^{-4} \mathrm{~s}^{-1}$ for the reference strain rate $\dot{\varepsilon}_{\text {ref }}$ and the rate hardening constant $C$ is $2.2392 \times 10^{-2}$.

Rate Hardening Multiplier

$\Gamma(\dot{\varepsilon})=1+\operatorname{Cln}\left(\frac{\dot{\varepsilon}}{\dot{\varepsilon_{r e f}}}\right)$

Table 2 Tensile testing values for Vanadis 8

\begin{tabular}{ll}
\hline Total strain & Stress $(\mathrm{MPa})$ \\
\hline 0.001 & 218 \\
0.002 & 436 \\
0.005 & 1100 \\
0.009 & 1780 \\
0.013 & 2280 \\
0.0135 & 2335 \\
0.0155 & 2460 \\
\hline
\end{tabular}

\subsection{Inverse calibration of material model parameters}

The inverse calibration of the material model parameters was done with 2nd degree polynomial response surface method (Eq. 5) using a cutting speed, a friction coefficient, the maximum flow stress, a thermal softening modifier, and the rate hardening coefficient as variables, and the output criteria were the force components. Crosstalk between the parameters was included by multiplying the individual polynomials like in Eq. 6. A total of 25 calibration simulations were performed to find parameters that gave acceptable error in the final simulations. The response surface itself was optimized after every additional calibration simulation and after 25 simulations, the response surface error was $5 \%$. The final optimal output of the response surface for the maximum flow stress, the rate hardening coefficient, and the thermal softening modifier and friction are given in the above material data sets. The response surface parameters that gave the optimal values are shown in Table 3 .

Polynomial response surface for " $x$ " where " $x$ " denotes any of the input variables and " $i$ " denotes the force component

$p_{x i}(x)=a_{x i} x^{2}+b_{x i} x+c_{x i}$

Total crosstalk effect of all variables for force component "i"

$P_{F i}=p_{v i} p_{\sigma i} p_{R i} p_{T i} p_{f i}$

\section{Results}

The results of the experiments and simulations are presented for tool wear, cutting forces, thermal behavior, chip morphology, and residual plastic strain on the workpiece surface. 
Figure 10 Vanadis 8 strain hardening properties

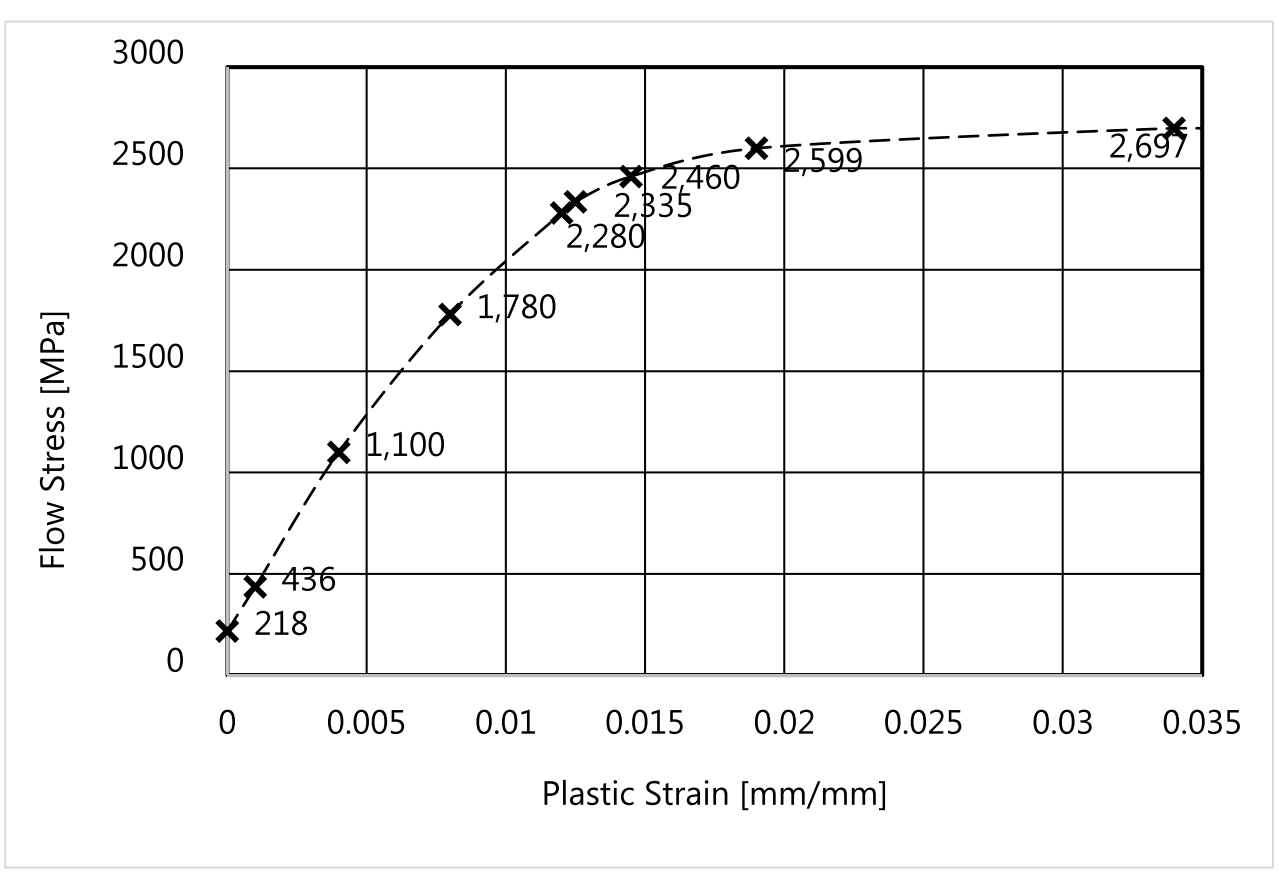

\subsection{Tool wear}

Tool wear data is presented as data points and corresponding Logit-model fit (presented with line) shown in Figure 12. The difference between subcooled MQL and regular MQL is small, but one might see a slight tool life benefit in favor of the subcooled MQL. The Logit-model parameters and Taylor's model parameters are shown in Table 4.

\subsection{Cutting forces}

Cutting forces from subcooled MQL experiments and simulations are shown in Figure 13, Figure 14, and Figure 15. The experimental forces are extracted from the measurement date from the time interval where the tool wear was equivalent of $\mathrm{V}_{\mathrm{B}} 80 \mu \mathrm{m}$. Total average error of the simulated cutting forces on the second revolution compared with experimentally determined values is $2.6 \%$ and maximum error is $5.2 \%$ at $100 \mathrm{~m} /$ min regarding the passive force. The same errors for the first revolution are $28 \%$ and $42 \%$, which clearly indicates that the previously deformed layer has significant effect on the flow stress properties of the work material, and thus, the cutting forces. The results for the regular MQL experiments and simulations are shown in Figure 16, Figure 17, and Figure 18. The obtained forces do not have any significant difference compared with the subcooled MQL forces. The simulations are also in good agreement with the experiments, average error being $3 \%$ and maximum individual error $5.1 \%$.
Figure 11 Vanadis 8 thermal softening properties

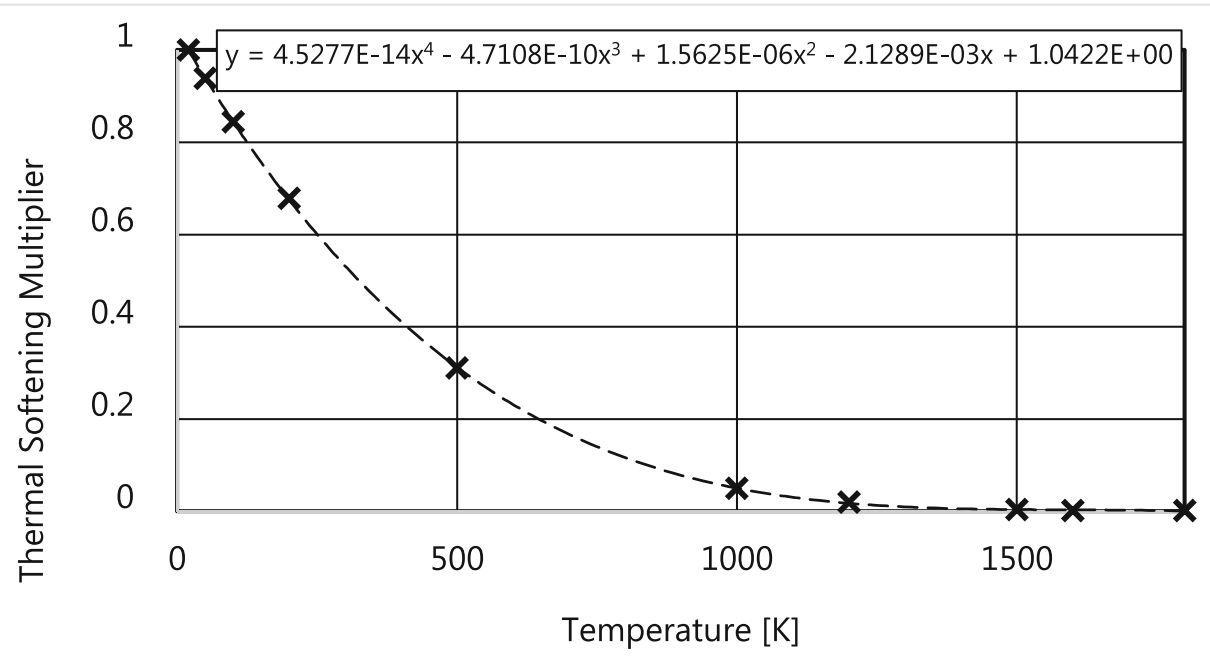


Table 3 Response surface parameters

\begin{tabular}{llllll}
\hline & Cutting speed & Yield stress & Rate hardening & Thermal softening & Friction \\
\hline$a_{F P}$ & 0.000032 & -0.001417 & -0.350907 & 672.970493 & -0.669547 \\
$b_{F P}$ & -0.573461 & 29.696814 & 0.052353 & 1.864756 & 0.815178 \\
$c_{F P}$ & 545.92841 & -19.174668 & 0.002508 & 0.002627 & 1.106154 \\
$a_{F C}$ & -0.013566 & -0.000241 & -24.9349 & 12.935081 & -0.383957 \\
$b_{F C}$ & 1.83917 & 14.99501 & 4.544994 & 0.040691 & 0.690395 \\
$c_{F C}$ & 161.79428 & -33.494304 & 0.261983 & 0.000069 & 1.271032 \\
$a_{F T}$ & -0.018125 & -0.0002 & -10.58965 & 4837.321285 & -0.002124 \\
$b_{F T}$ & 2.161617 & 7.396141 & 1.56874 & 13.951823 & 0.002338 \\
$c_{F T}$ & 649.12125 & -99.143707 & 0.074924 & 0.021536 & 0.003834 \\
\hline
\end{tabular}

Table 4 Logit-model parameters and Taylor's model parameters

cBN-Vanadis 8 subcooled MQL cBN-Vanadis 8 regular MQL

\begin{tabular}{lll}
\hline $\mathrm{a}$ & -0.045 & 0.022 \\
$\mathrm{~b}$ & 0.421 & 0.75 \\
$\mathrm{~m}$ & $9.344 \times 10^{-3}$ & $9.592 \times 10^{-3}$ \\
$\mathrm{VB}_{\max }$ & 0.202 & 0.223 \\
$\mathrm{C}$ & 323.361 & 323.361 \\
$\mathrm{n}$ & -1.932 & -1.932 \\
\hline
\end{tabular}

\subsection{Chip morphology}

The chip shapes from simulations are presented in Figure 19. The chip formation is continuous, as observed in the experiments as well. The chip has a distinct curl that also was noticed in the experiments, as shown in Figure 20. The simulated chip width at $100 \mathrm{~m} / \mathrm{min}$ cutting speed with subcooled MQL is $0.58 \mathrm{~mm}$ while the corresponding chip width from the experiment is $0.537 \mathrm{~mm}$, so there is an acceptable $8 \%$ error. The chip width also increased in simulations after the first cutting
Figure 12 Tool wear with MQL and subcooled MQL at different cutting speeds and the Logitmodel representation of the data

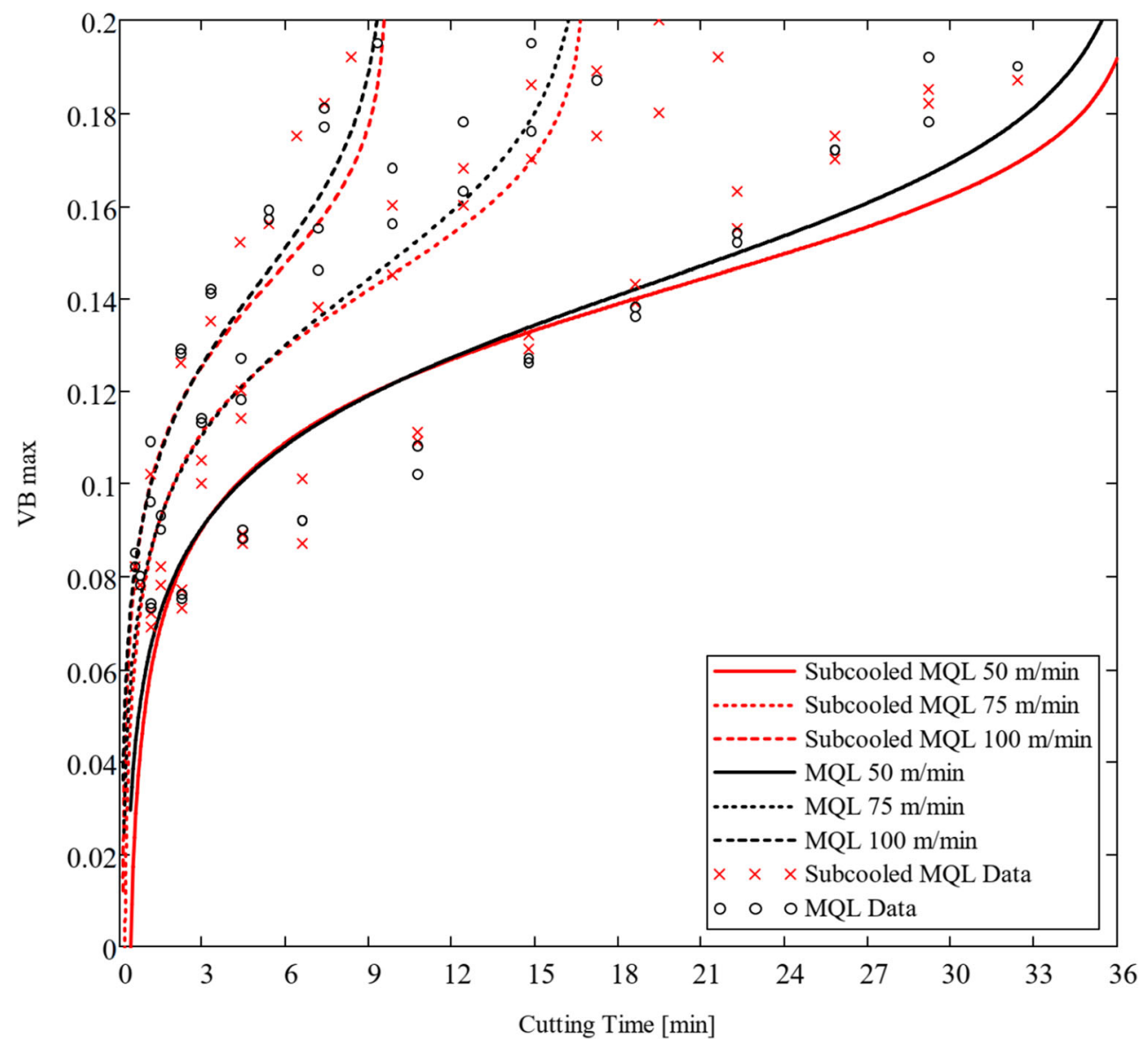


Figure 13 Experimental and simulated cutting forces at $50 \mathrm{~m} /$ min cutting speed with subcooled MQL

Figure 14 Experimental and simulated cutting forces at $75 \mathrm{~m} /$ min cutting speed with subcooled MQL
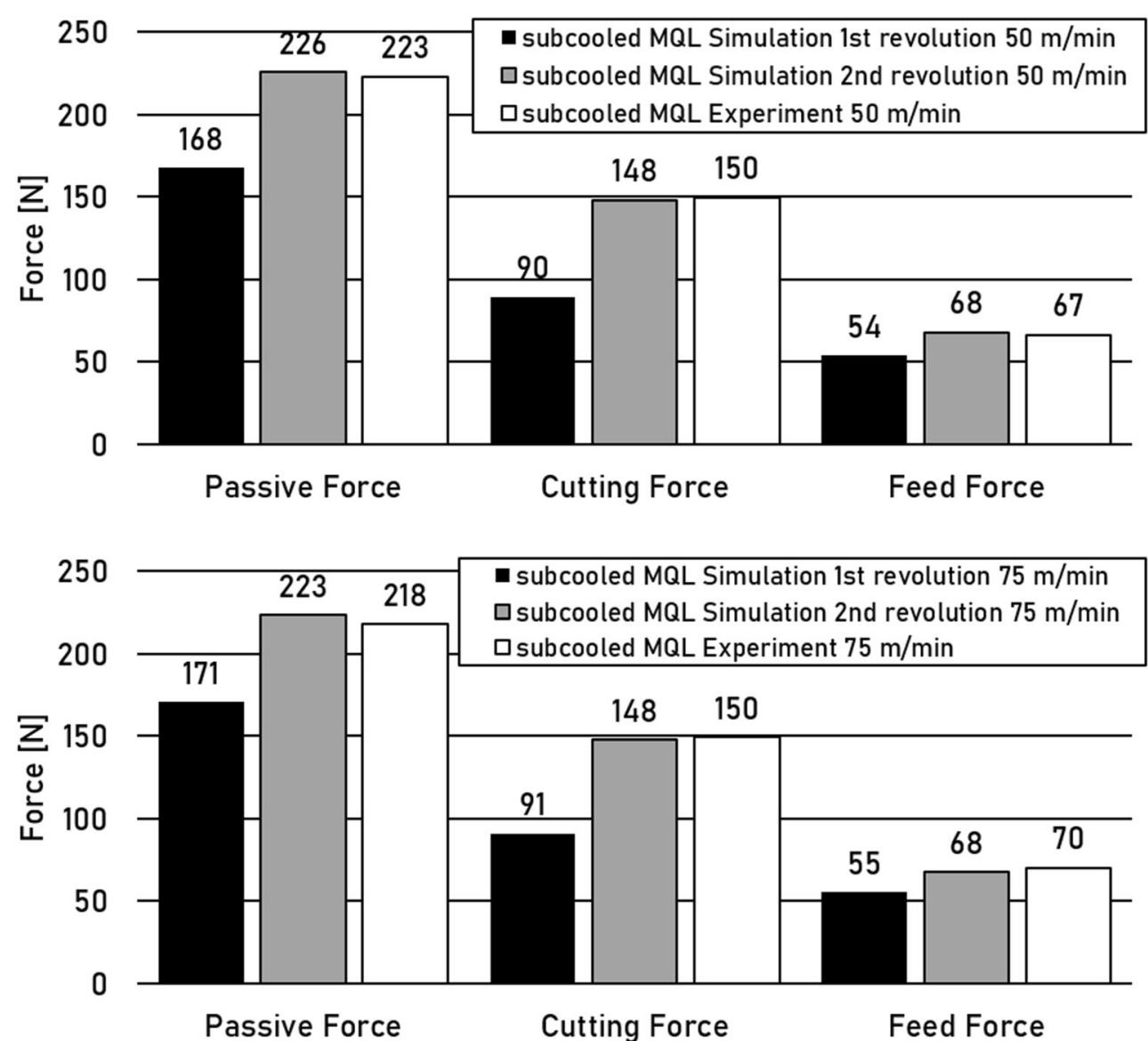

pass where the initial width was $0.48 \mathrm{~mm}$. The chip width was not observed to change significantly with different cutting speeds or with the use of subcooled MQL or regular MQL. engagement ended decreased slightly faster with the subcooled MQL compared with regular MQL, and the maximum tool temperature was $176{ }^{\circ} \mathrm{C}$ with subcooled MQL and $178^{\circ} \mathrm{C}$ with regular MQL.

\subsection{Residual strain}

Figure 21 shows the measurement points where the residual plastic strain was extracted from the simulations. Figure 22 and Figure 23 show the extracted data from simulations with
Figure 15 Experimental and simulated cutting forces at $100 \mathrm{~m} /$ min cutting speed with subcooled MQL

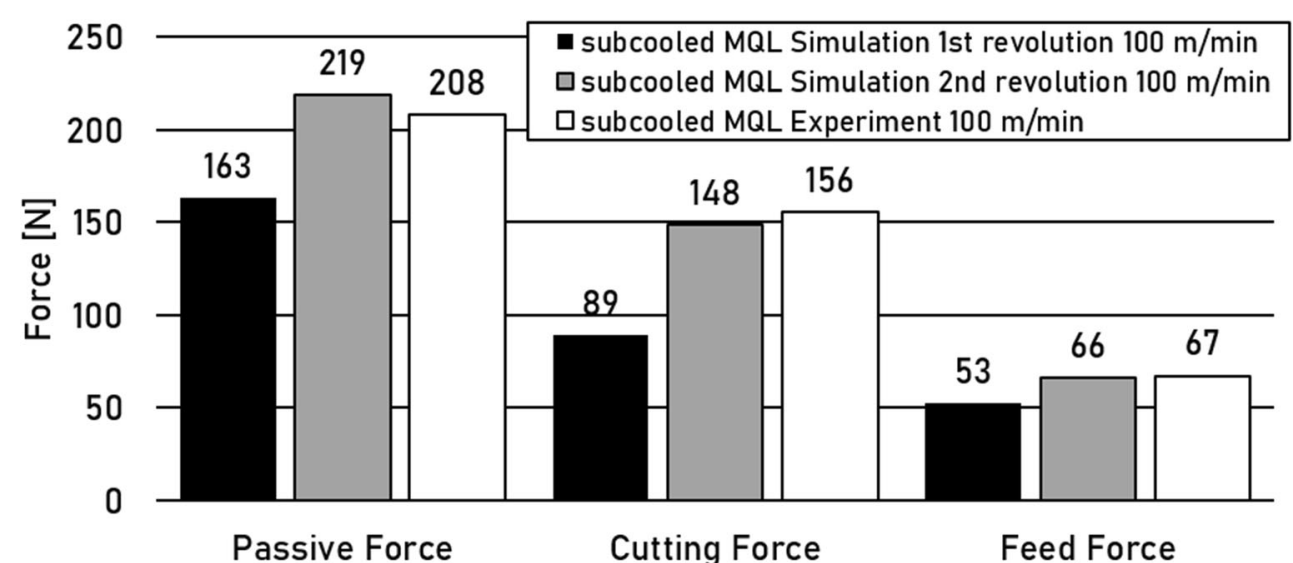


Figure 16 Experimental and simulated cutting forces at $50 \mathrm{~m} /$ min cutting speed with MQL

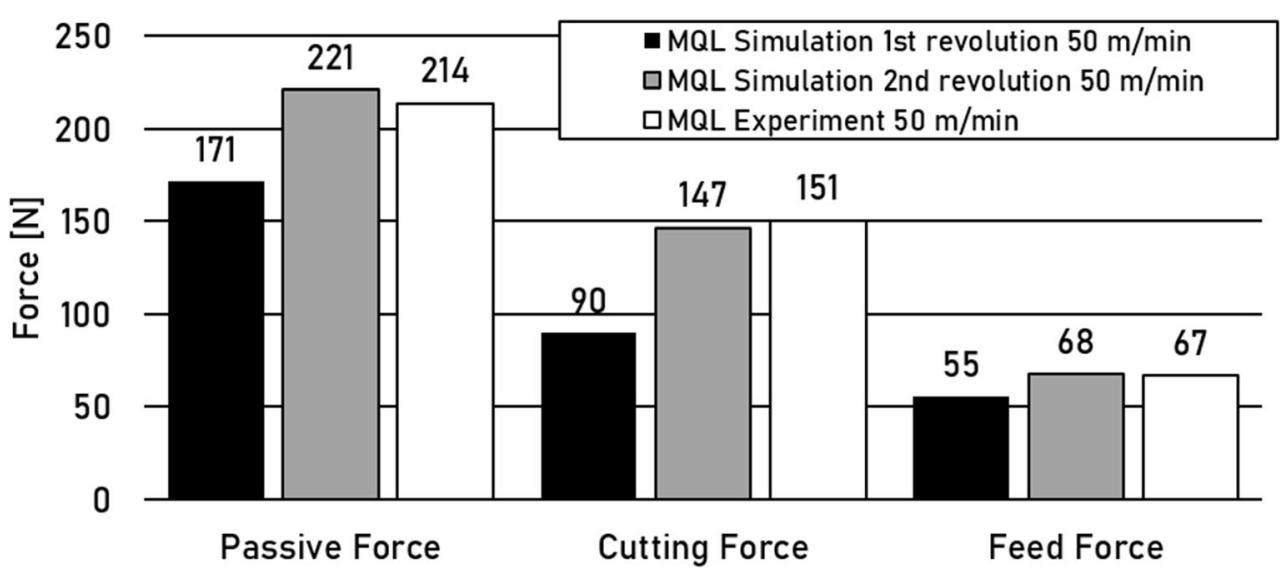

subcooled MQL and regular MQL. The Von Mises plastic strain is very high even up to $1 \mathrm{~mm}$ into the workpiece. It should be noted that these results have not been experimentally verified, but similar magnitude strains have been reported in hard machining for example in Sales et al. (2020) [71]. The difference between the subcooled MQL and regular MQL is relatively small. The strain increases by about $50 \%$ even after the second tool pass. One additional set of simulations was done to evaluate the residual strain formation with regard to the cooling-lubrication effect. In these simulations, the subcooled MQL windows were extended to the flank side of the tool, thus simulating two MQL nozzles, one on the rake face and other on the flank face. The simulation results are shown in Figure 24, where the residual stains from the subcooled MQL, regular MQL, and the dual-nozzle subcooled MQL at $100 \mathrm{~m} / \mathrm{min}$ are compared. It can be seen
Figure 17 Experimental and simulated cutting forces at $75 \mathrm{~m} /$ min cutting speed with MQL
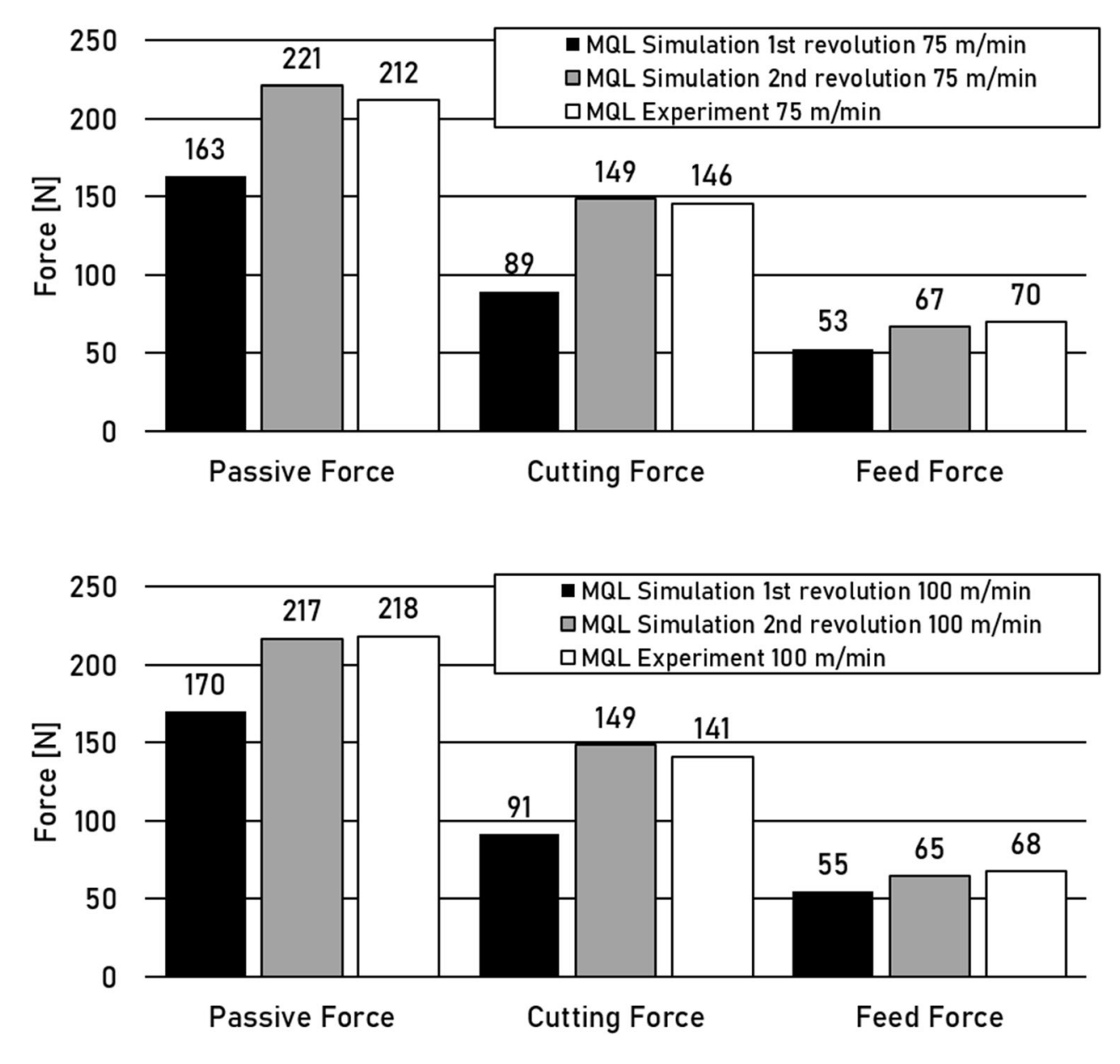

Figure 18 Experimental and simulated cutting forces at $100 \mathrm{~m} /$ min cutting speed with MQL 
Figure 19 Simulation output after 2nd revolution; left subcooled MQL, right MQL; from top down; 50, 75, and 100 $\mathrm{m} / \mathrm{min}$
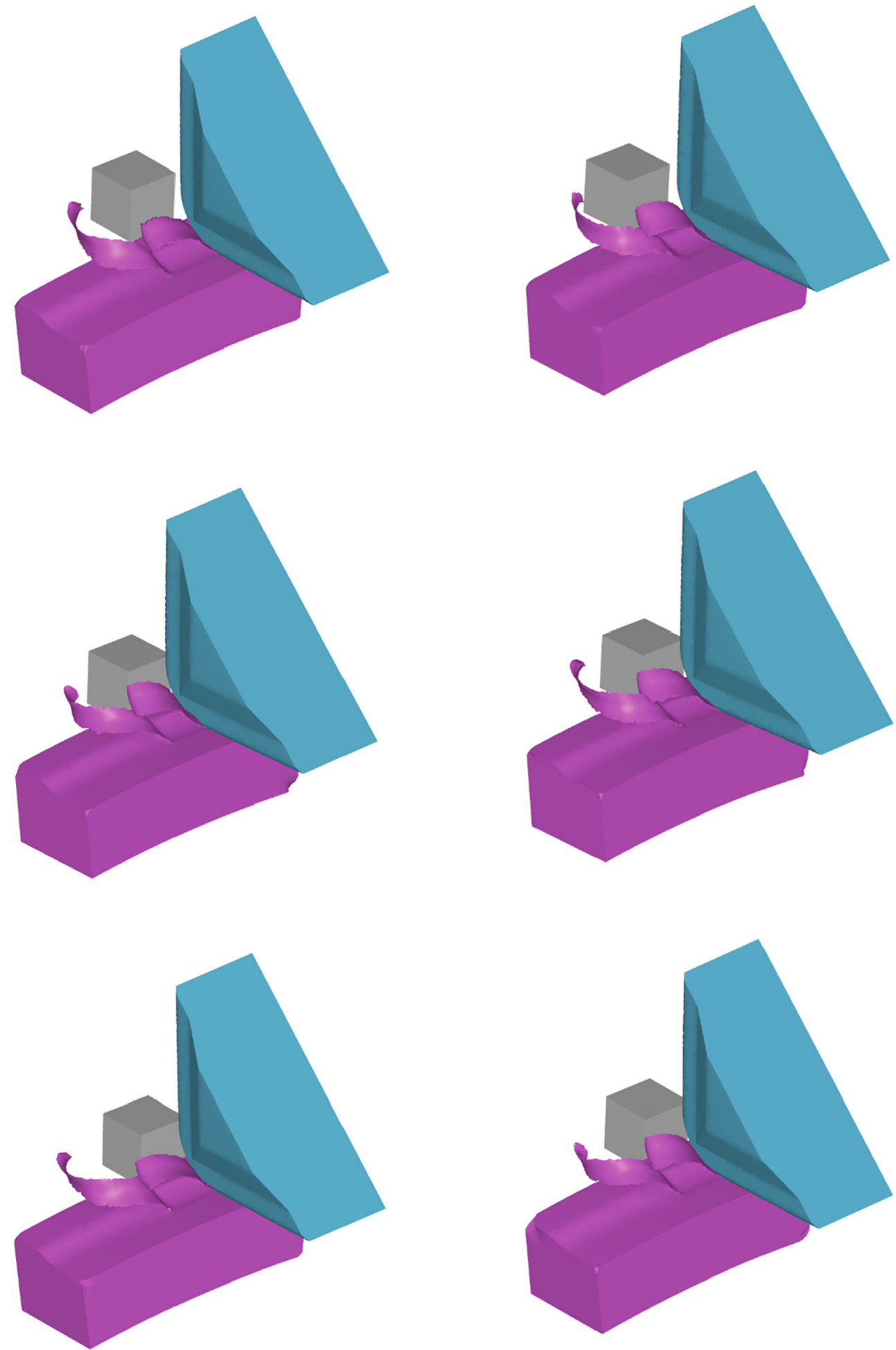

that the subcooled MQL with dual nozzles produced least residual strains $(-76 \%$ on average compared to regular MQL), then subcooled MQL ( $-11 \%$ on average compared to regular MQL), and the regular MQL produced highest residual strains. This clearly indicates the significance of correct nozzle placement.

\section{Discussion and conclusions}

This paper investigated the subcooled MQL compared with regular MQL with simulations and experiments. The following conclusions were made: 
Figure 20 Chip curl observed from cutting experiments at 100 $\mathrm{m} / \mathrm{min}$

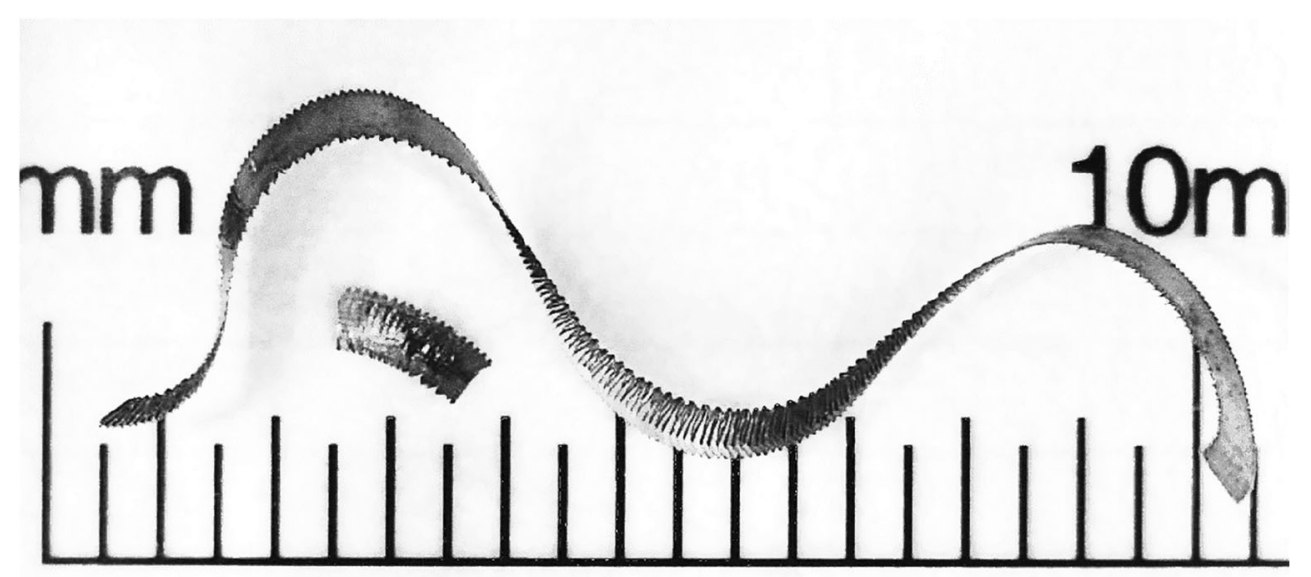

- The simulation accuracy is acceptable when the material model is calibrated correctly at the second tool pass, especially the feed force errors that have been omnipresent in cutting simulations were diminished.

- The subcooled MQL had only slightly better performance over the regular MQL. The small difference is due to highly abrasive work material, which causes high wear rate regardless of temperature.

- Optimizing the nozzle placement for MQL is critical and it has a significant effect on the surface residual strains.

- Simulations suggest that friction coefficient increases with increasing cutting speed with vegetable oil MQL.

- Modeling of the heat transfer of coolants in metal cutting is not sufficiently developed in existing research.
Compared with regular MQL, subcooling the MQL to $-10{ }^{\circ} \mathrm{C}$ has a small beneficial effect on the cutting force, tool wear, and cutting temperature, observed with experiments and simulations. One of the reasons why there is no more significant difference is the high abrasivity of Vanadis 8 , which leads to high abrasive wear of the tool, which is not sensitive to temperature. Optimizing the delivery of the subcooled MQL is expected to improve the tool wear, since the direct delivery of the lubricant at the flank face of the tool should improve the contact conditions. Also, the surface integrity of the machined surface is expected to improve with better lubrication and cooling at the flank face that was already predicted with the trial simulations done in this paper.
Figure 21 Residual plastic strain extraction points

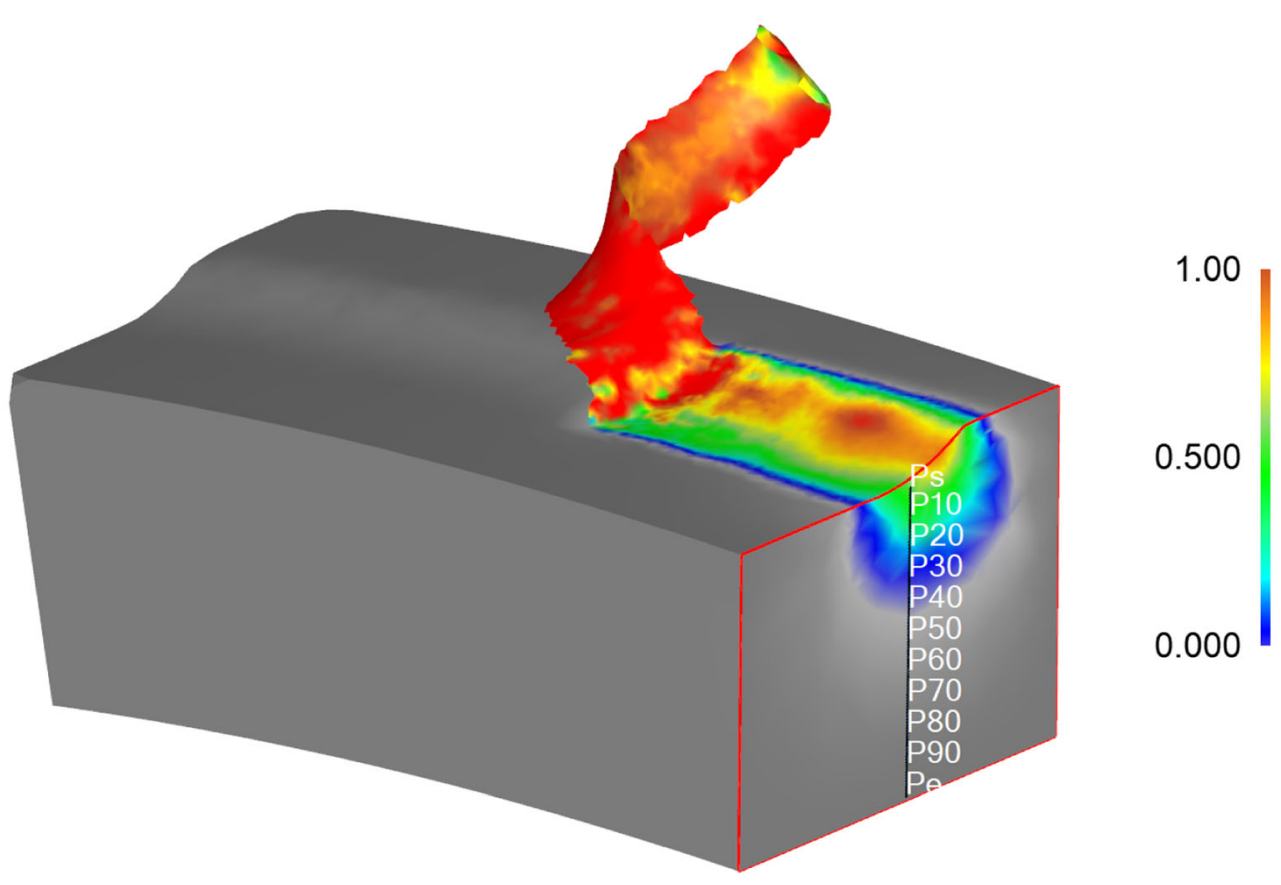




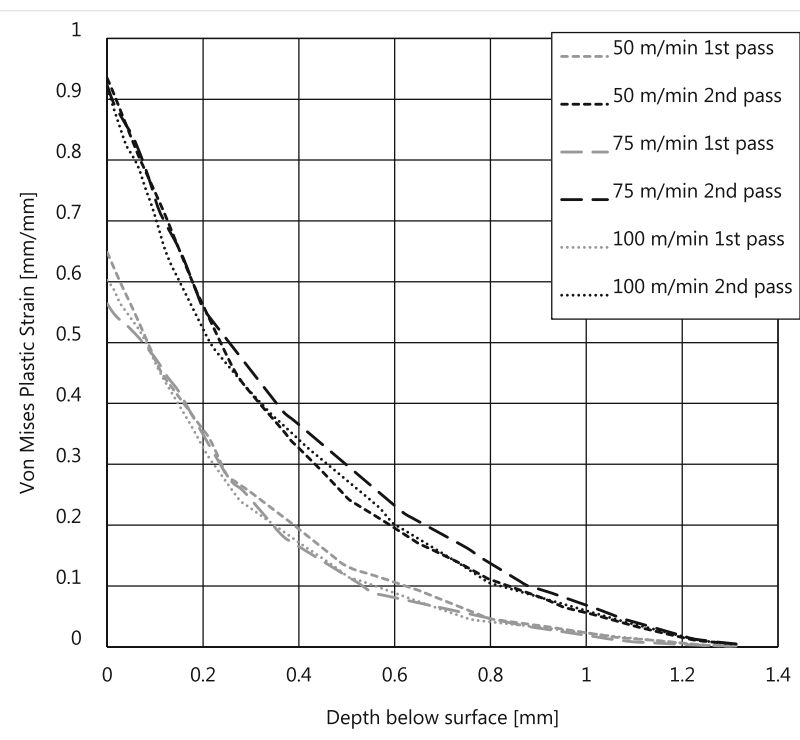

Figure 22 Residual plastic strain after 1 st and 2 nd tool pass with subcooled MQL

The lubricative effect of the MQL was investigated with friction coefficient. The simulations suggest that the friction coefficient increases with increasing cutting speed. The literature review supports this behavior and the possible reasons for this are the change in the behavior of the oil in high pressure and temperature and inadequate volume of the lubrication oil flow, which both have more significant effect when the cutting speed is higher. The second nozzle is expected to improve the lubrication even at higher cutting speeds.

Simulations show that the second tool pass over the workpiece increases cutting forces because the surface layer of the workpiece is deformed during the initial tool pass, which can be well observed from the residual strain diagrams above. This has major implications for inverse determination of material properties: if the inverse method is used with simulations that have only one cutting pass, and the simulated workpiece material is not previously deformed, the inverse model gives overestimated values for flow stress. The researchers in the field often disregard this notion by stating that a pristine workpiece was used in the experiments, but do not realize that in every cutting operation, the surface is not pristine after the first revolution of the tool or the workpiece. Only broaching is capable of a long cutting pass with a pristine material, but even with this operation, the workpiece surface is deformed during the second pass, and the same error exists for any consecutive tool passes. Another notable fact is that if the simulations are modeled with real tool wear geometry and
Figure 23 Residual plastic strain after 1 st and 2 nd tool pass with regular MQL

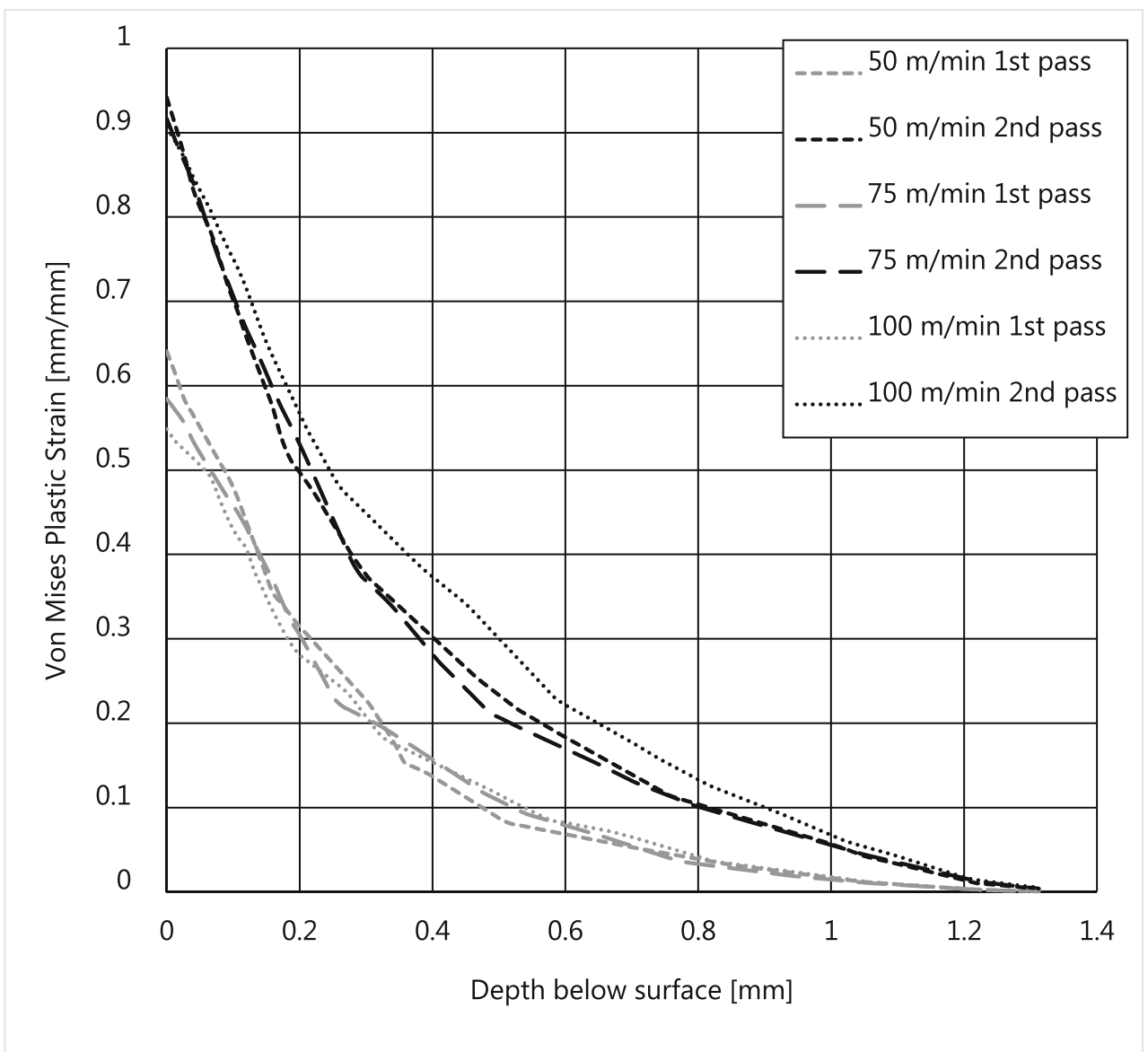


Figure 24 Comparison of residual plastic strain after 1 st and 2nd tool pass at $100 \mathrm{~m} / \mathrm{min}$

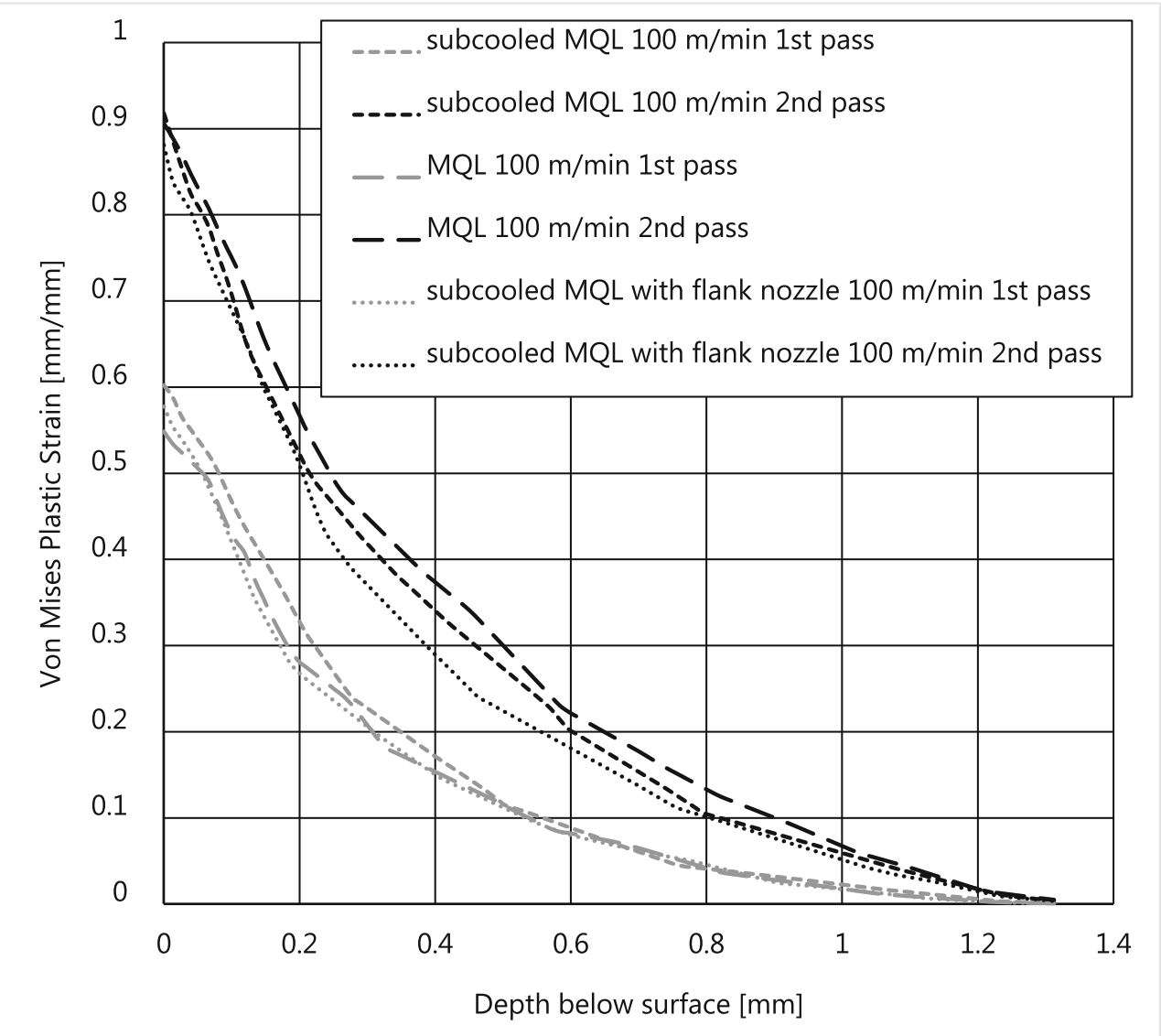

multiple tool passes, the ever-existing feed force error disappears. This paper provided further evidence of the notions about the importance of tool geometry, the initial wear of the tool, and surface properties of the workpiece made in Laakso et al. $(2018,2019,2020)[48,49,65]$. The simulation model needs to be further improved by calibrating the heat transfer coefficients using experimental setup with IR camera.

Author contribution Sampsa Laakso collaborated in the design of experiments, developed the simulation models and inverse analysis routines, did the literature review, wrote the manuscript, and analyzed the results.

Dinesh Mallipeddi did the design of experiments, conducted the experiments and microscopy, and participated in the writing process and analysis of the results.

Peter Krajnik acquired the funding, provided the facilities for the research, and participated in the writing process and quality assurance.

Funding Open access funding provided by Chalmers University of Technology. This work was performed under the sponsorship of the "Strategic vehicle research and innovation (FFI)" program (project SUSTAIN-CRYO, 2017-03057) - a partnership program run jointly by the Swedish state and Swedish automotive industry.

Data Availability All data and materials are presented in the paper
Code availability The FEM solver used in this work is Scientific Forming Technologies Deform, which is commercially available software.

\section{Declarations}

Ethics approval This paper does not include any ethical considerations.

Consent to participate Not applicable as no humans or animals were the object of the research.

Consent for publication All the authors agree on publishing this work in the International Journal of Advanced Manufacturing Technology.

Competing interests The authors declare no competing interests.

Open Access This article is licensed under a Creative Commons Attribution 4.0 International License, which permits use, sharing, adaptation, distribution and reproduction in any medium or format, as long as you give appropriate credit to the original author(s) and the source, provide a link to the Creative Commons licence, and indicate if changes were made. The images or other third party material in this article are included in the article's Creative Commons licence, unless indicated otherwise in a credit line to the material. If material is not included in the article's Creative Commons licence and your intended use is not permitted by statutory regulation or exceeds the permitted use, you will need to obtain permission directly from the copyright holder. To view a copy of this licence, visit http://creativecommons.org/licenses/by/4.0/. 


\section{References}

1. Moore JM (1977) Small is beautiful - the Volvo experiment. In: Proc AIIE Annu Conf Conv For Spring Annu Conf and Prod Eng Show. AIIE, Dallas, pp 460-465

2. Ong SK, Koh TH, Nee AYC (2001) Assessing the environmental impact of materials processing techniques using an analytical hierarchy process method. J Mater Process Technol 113:424-431. https://doi.org/10.1016/S0924-0136(01)00618-5

3. Senthil Kumaran D, Ong SK, Tan RBH, Nee AYC (2001) Environmental life cycle cost analysis of products. Environ Manag Health 12:260-276. https://doi.org/10.1108/ 09566160110392335

4. Duflou JR, Sutherland JW, Dornfeld D, Herrmann C, Jeswiet J, Kara S, Hauschild M, Kellens K (2012) Towards energy and resource efficient manufacturing: a processes and systems approach. CIRP Ann - Manuf Technol 61:587-609. https://doi.org/10.1016/j. cirp.2012.05.002

5. Teece DJ (2007) Explicating dynamic capabilities: the nature and microfoundations of (sustainable) enterprise performance. Strateg Manag J 28:1319-1350. https://doi.org/10.1002/smj.640

6. Jayal AD, Badurdeen F, Dillon OW, Jawahir IS (2010) Sustainable manufacturing: modeling and optimization challenges at the product, process and system levels. CIRP J Manuf Sci Technol 2:144 152. https://doi.org/10.1016/j.cirpj.2010.03.006

7. Pusavec F, Krajnik P, Kopac J (2010) Transitioning to sustainable production - part I: application on machining technologies. J Clean Prod 18:174-184. https://doi.org/10.1016/j.jclepro.2009.08.010

8. Sivaiah P, Chakradhar D (2018) Effect of cryogenic coolant on turning performance characteristics during machining of 17-4 $\mathrm{PH}$ stainless steel: a comparison with MQL, wet, dry machining. CIRP J Manuf Sci Technol 21:86-96. https://doi.org/10.1016/j.cirpj. 2018.02.004

9. Pušavec F, Grguraš D, Koch M, Krajnik P (2019) Cooling capability of liquid nitrogen and carbon dioxide in cryogenic milling. CIRP Ann 68:73-76. https://doi.org/10.1016/j.cirp.2019.03.016

10. Avram O, Stroud I, Xirouchakis P (2011) A multi-criteria decision method for sustainability assessment of the use phase of machine tool systems. Int J Adv Manuf Technol 53:811-828. https://doi.org/ 10.1007/s00170-010-2873-2

11. Sultana MN, Dhar NR, Zaman PB (2019) A review on different cooling / lubrication techniques in metal cutting. Am J Mech Appl 7:71-87. https://doi.org/10.11648/j.ajma.20190704.11

12. Sankaranarayanan R, Rajesh Jesudoss Hynes N, Senthil Kumar J, Krolczyk GM (2021) A comprehensive review on research developments of vegetable-oil based cutting fluids for sustainable machining challenges. J Manuf Process 67:286-313. https://doi.org/ 10.1016/j.jmapro.2021.05.002

13. Khan AM, He N, Li L, Zhao W, Jamil M (2020) Analysis of productivity and machining efficiency in sustainable machining of titanium alloy. Procedia Manuf 43:111-118. https://doi.org/10.1016/ j.promfg.2020.02.122

14. Sudheer N, Rao KVJ, Das VC (2014) Investigation on influence of refrigerated air and high heat transfer rate MQL in turning of aluminium metal matrix composite. In: 5th International \& 26th All India Manufacturing Technology, Design and Research Conference (AIMTDR 2014), IIT Guwahati, Assam, India 12th. pp 451-454

15. Tasdelen B, Thordenberg H, Olofsson D (2008) An experimental investigation on contact length during minimum quantity lubrication (MQL) machining. J Mater Process Technol 203:221-231. https://doi.org/10.1016/j.jmatprotec.2007.10.027

16. Boswell B, Islam MN, Davies IJ, Ginting YR, Ong AK (2017) A review identifying the effectiveness of minimum quantity lubrication (MQL) during conventional machining. Int J Adv Manuf Technol 92:321-340. https://doi.org/10.1007/s00170-017-0142-3
17. Tasdelen B, Wikblom T, Ekered S (2008) Studies on minimum quantity lubrication (MQL) and air cooling at drilling. J Mater Process Technol 200:339-346. https://doi.org/10.1016/j. jmatprotec.2007.09.064

18. Khanna N, Agrawal C, Pimenov DY, Singla AK, Machado AR, da Silva LRR, Gupta MK, Sarikaya M, Krolczyk GM (2021) Review on design and development of cryogenic machining setups for heat resistant alloys and composites. J Manuf Process 68:398-422. https://doi.org/10.1016/j.jmapro.2021.05.053

19. Bihagen S, Kopac J, Krajnik P, et al (2016) A lubrication and cooling device and a method for lubricating and cooling a work piece. 29

20. Barron RF, Nellis GF (2017) Cryogenic heat transfer. CRC press, Boca Raton

21. Shokrani A, Dhokia V, Newman ST (2017) Hybrid cooling and lubricating technology for CNC milling of Inconel 718 nickel alloy. Procedia Manuf 11:625-632. https://doi.org/10.1016/j.promfg. 2017.07.160

22. Yıldırım ÇV, Kıvak T, Sarıkaya M, Șirin Ș (2020) Evaluation of tool wear, surface roughness/topography and chip morphology when machining of Ni-based alloy 625 under MQL, cryogenic cooling and CryoMQL. J Mater Res Technol 9:2079-2092. https://doi.org/10.1016/j.jmrt.2019.12.069

23. Olsson M, Akujärvi V, Ståhl J-E, Bushlya V (2021) Cryogenic and hybrid induction-assisted machining strategies as alternatives for conventional machining of refractory tungsten and niobium. Int $\mathbf{J}$ Refract Met Hard Mater 97:105520. https://doi.org/10.1016/j. ijrmhm.2021.105520

24. Salame C, Bejjani R, Marimuthu P (2019) A better understanding of cryogenic machining using CFD and FEM simulation. Proc CIRP 81:1071-1076. https://doi.org/10.1016/j.procir. 2019.03.255

25. Pereira O, Rodríguez A, Barreiro J, Fernández-Abia AI, de Lacalle LNL (2017) Nozzle design for combined use of MQL and cryogenic gas in machining. Int J Precis Eng Manuf Technol 4:87-95. https://doi.org/10.1007/s40684-017-0012-3

26. Hribersek M, Sajn V, Pusavec F, Rech J, Kopac J (2017) The procedure of solving the inverse problem for determining surface heat transfer coefficient between liquefied nitrogen and Inconel 718 workpiece in cryogenic machining. Proc CIRP 58:617-622. https:// doi.org/10.1016/j.procir.2017.03.227

27. Sun Y, Huang B, Puleo DA, Jawahir IS (2015) Enhanced machinability of Ti-5553 alloy from cryogenic machining: comparison with MQL and flood-cooled machining and modeling. Proc CIRP 31:477-482. https://doi.org/10.1016/j.procir.2015.03.099

28. Kaynak Y, Gharibi A, Ozkutuk M (2018) Experimental and numerical study of chip formation in orthogonal cutting of Ti-5553 alloy: the influence of cryogenic, MQL, and high pressure coolant supply. Int J Adv Manuf Technol 94:1411-1428. https://doi.org/10.1007/ s00170-017-0904-y

29. Umbrello D, Caruso S, Imbrogno S (2016) Finite element modelling of microstructural changes in dry and cryogenic machining AISI 52100 steel. Mater Sci Technol 32:1062-1070. https://doi. org/10.1080/02670836.2015.1104085

30. Astakhov VP, Joksch S (2012) Metalworking fluids (MWFs) for cutting and grinding: fundamentals and recent advances. Elsevier Science

31. Imbrogno S, Sartori S, Bordin A, Bruschi S, Umbrello D (2017) Machining simulation of Ti6Al4V under dry and cryogenic conditions. Proc CIRP 58:475-480. https://doi.org/10.1016/j.procir. 2017.03.263

32. Davoudinejad A, Chiappini E, Tirelli S, Annoni M, Strano M (2015) Finite element simulation and validation of chip formation and cutting forces in dry and cryogenic cutting of Ti-6Al-4V. Procedia Manuf 1:728-739. https://doi.org/10.1016/j.promfg. 2015.09.037 
33. Mishra SK, Ghosh S, Aravindan S (2019) FEM based evaluation of Ti6Al4V cutting with plain and textured WC/Co tools under cryogenic cooling environment. Procedia Manuf 40:8-13. https://doi. org/10.1016/j.promfg.2020.02.003

34. Dix M, Wertheim R, Schmidt G, Hochmuth C (2014) Modeling of drilling assisted by cryogenic cooling for higher efficiency. CIRP Ann - Manuf Technol 63:73-76. https://doi.org/10.1016/j.cirp. 2014.03.080

35. Farrokh B, Khan AS (2009) Grain size, strain rate, and temperature dependence of flow stress in ultra-fine grained and nanocrystalline $\mathrm{Cu}$ and $\mathrm{Al}$ : synthesis, experiment, and constitutive modeling. Int J Plast 25:715-732. https://doi.org/10.1016/j. ijplas.2008.08.001

36. CURLE UA, GOVENDER G (2010) Semi-solid rheocasting of grain refined aluminum alloy 7075. Trans Nonferrous Metals Soc China 20:s832-s836. https://doi.org/10.1016/S1003-6326(10) 60590-0

37. Rotella G, Umbrello D (2014) Numerical simulation of surface modification in dry and cryogenic machining of AA7075 Alloy. Proc CIRP 13:327-332. https://doi.org/10.1016/j.procir.2014.04. 055

38. Su Y (2015) Investigation into the role of cooling/lubrication effect of cryogenic minimum quantity lubrication in machining of AISI H13 steel by three-dimensional finite element method. Proc Inst Mech Eng Part B J Eng Manuf 230:1003-1016. https://doi.org/ 10.1177/0954405414564806

39. Shi B, Elsayed A, Damir A, Attia H, M'Saoubi R (2019) A hybrid modeling approach for characterization and simulation of cryogenic machining of Ti-6Al-4V alloy. J Manuf Sci Eng 141. https://doi. org/10.1115/1.4042307

40. Umbrello D, Rizzuti S, Outeiro JC, Shivpuri R, M'Saoubi R (2008) Hardness-based flow stress for numerical simulation of hard machining AISI H13 tool steel. J Mater Process Technol 199:64-73. https://doi.org/10.1016/j.jmatprotec.2007.08.018

41. Yan H, Hua J, Shivpuri R (2007) Flow stress of AISI H13 die steel in hard machining. Mater Des 28:272-277. https://doi.org/10.1016/ j.matdes.2005.06.017

42. Saez-de-Buruaga M, Gainza L, Aristimuno P, Soler D, Ortiz-deZarate G, Aizpuru O, Mielgo R, Arrazola PJ (2019) FEM modeling of hard turning 42CrMoS4 steel. Proc CIRP 82:77-82. https://doi. org/10.1016/j.procir.2019.04.059

43. Yadav RK, Abhishek K, Mahapatra SS (2015) A simulation approach for estimating flank wear and material removal rate in turning of Inconel 718. Simul Model Pract Theory 52:1-14. https://doi. org/10.1016/j.simpat.2014.12.004

44. Binder M, Klocke F, Lung D (2015) Tool wear simulation of complex shaped coated cutting tools. Wear 330-331:600-607. https:// doi.org/10.1016/j.wear.2015.01.015

45. Binder M, Klocke F, Doebbeler B (2017) An advanced numerical approach on tool wear simulation for tool and process design in metal cutting. Simul Model Pract Theory 70:65-82. https://doi. org/10.1016/j.simpat.2016.09.001

46. Schulze V, Zanger F (2011) Development of a simulation model to investigate tool wear in Ti-6Al-4V alloy machining. In: Advanced Materials Research. pp 535-544

47. Yen Y-C, Söhner J, Lilly B, Altan T (2004) Estimation of tool wear in orthogonal cutting using the finite element analysis. J Mater Process Technol 146:82-91. https://doi.org/10.1016/S09240136(03)00847-1

48. Laakso SVA, Zhao T, Agmell M, et al (2017) Too sharp for its own good - tool edge deformation mechanisms in the initial stages of metal cutting. In: Procedia Manufacturing: 27th International Conference on Flexible Automation and Intelligent Manufacturing, FAIM2017, 27-30 June 2017, Modena, Italy. Elsevier, Lund
49. Laakso SVA, Agmell M, Ståhl J-E (2018) The mystery of missing feed force - the effect of friction models, flank wear and ploughing on feed force in metal cutting simulations. J Manuf Process 33:268277. https://doi.org/10.1016/j.jmapro.2018.05.024

50. Peng B, Bergs T, Klocke F, Döbbeler B (2019) An advanced FEmodeling approach to improve the prediction in machining difficult-to-cut material. Int J Adv Manuf Technol 103:21832196. https://doi.org/10.1007/s00170-019-03456-0

51. Tamizharasan T, Senthil Kumar N (2012) Optimization of cutting insert geometry using DEFORM-3D: numerical simulation and experimental validation. Int J Simul Model 11:65-76. https://doi.org/ 10.2507/IJSIMM11(2)1.200

52. Szczotkarz N, Mrugalski R, Maruda RW, Królczyk GM, Legutko S, Leksycki K, Dębowski D, Pruncu CI (2021) Cutting tool wear in turning $316 \mathrm{~L}$ stainless steel in the conditions of minimized lubrication. Tribol Int 156:106813. https://doi.org/10.1016/j.triboint.2020. 106813

53. Mane S, Karagadde S, Joshi SS, Kapoor SG (2020) Evaluation of an adhesive friction coefficient under extreme contact conditions and its application to the machining process. Tribol Trans 1-000. https://doi.org/10.1080/10402004.2020.1755757

54. Singh R, Bajpai V (2014) Coolant and lubrication in machining. In: Nee A (ed) Handbook of Manufacturing Engineering and Technology. Springer London, London, pp 1-34

55. Claudin C, Mondelin A, Rech J, Fromentin G (2010) Effects of a straight oil on friction at the toolworkmaterial interface in machining. Int J Mach Tools Manuf 50:681-688. https://doi.org/10.1016/j. ijmachtools.2010.04.013

56. Pottirayil A, Kailas SV, Biswas SK (2010) Experimental estimation of friction force in lubricated cutting of steel. Wear 269:557-564. https://doi.org/10.1016/j.wear.2010.05.012

57. Cassin C, Boothroyd G (1965) Lubricating action of cutting fluids. J Mech Eng Sci 7:67-81. https://doi.org/10.1243/jmes_jour_1965_ 007_012_02

58. Campen S, Green J, Lamb G, Atkinson D, Spikes H (2012) On the increase in boundary friction with sliding speed. Tribol Lett 48: 237-248. https://doi.org/10.1007/s11249-012-0019-4

59. Faverjon P, Rech J, Leroy R (2013) Influence of minimum quantity lubrication on friction coefficient and work-material adhesion during machining of cast aluminum with various cutting tool substrates made of polycrystalline diamond, high speed steel, and carbides. J Tribol 135:041602. https://doi.org/10.1115/1.4024546

60. Kaynak Y, Gharibi A, Yılmaz U, Köklü U, Aslantaş K (2018) A comparison of flood cooling, minimum quantity lubrication and high pressure coolant on machining and surface integrity of titanium Ti-5553 alloy. J Manuf Process 34:503-512. https://doi.org/10. 1016/j.jmapro.2018.06.003

61. Akmal M, Layegh KSE, Lazoglu I, Akgün A, Yavaș Ç (2017) Friction coefficients on surface finish of AlTiN coated tools in the milling of Ti6Al4V. Proc CIRP 58:596-600. https://doi.org/10. 1016/j.procir.2017.03.231

62. Laakso SVA, Johansson D (2019) There is logic in logit - including wear rate in Colding's tool wear model. Procedia Manuf 38:10661073. https://doi.org/10.1016/j.promfg.2020.01.194

63. Taylor FW (1907) On the art of cutting metals. American Society of mechanical engineers, New York

64. Lazoglu I, Islam C (2012) Modeling of 3D temperature fields for oblique machining. CIRP Ann - Manuf Technol 61:127-130. https://doi.org/10.1016/j.cirp.2012.03.074

65. Laakso SVA (2020) Damage does not cut it - saturated damage in FEM modelling of metal cutting breaks the simulation but not the chip. Procedia Manuf 51:806-811. https://doi.org/10.1016/j. promfg. 2020.10 .113

66. Agmell M, Bushlya V, M'Saoubi R, Gutnichenko O, Zaporozhets O, Laakso SVA, Ståhl JE (2020) Investigation of mechanical and thermal loads in pcBN tooling during machining of Inconel 718. Int 
J Adv Manuf Technol 107:1451-1462. https://doi.org/10.1007/ s00170-020-05081-8

67. Thepsonthi T, Özel T (2013) Experimental and finite element simulation based investigations on micro-milling Ti-6Al-4V titanium alloy: effects of cBN coating on tool wear. J Mater Process Technol 213:532-542. https://doi.org/10.1016/j.jmatprotec.2012.11.003

68. Solozhenko VL, Bushlya V, Zhou J (2019) Mechanical properties of ultra-hard nanocrystalline cubic boron nitride. J Appl Phys 126: 75107. https://doi.org/10.1063/1.5109636

69. Li J, Shao G, Ma Y, Zhao X, Wang H, Zhang R (2019) Processing and properties of polycrystalline cubic boron nitride reinforced by $\mathrm{SiC}$ whiskers. Int J Appl Ceram Technol 16:32-38. https://doi.org/ 10.1111/ijac. 13077
70. Özel T, Thepsonthi T, Ulutan D, Kaftanoğlu B (2011) Experiments and finite element simulations on micro-milling of Ti-6Al-4V alloy with uncoated and cBN coated micro-tools. CIRP Ann - Manuf Technol 60:85-88. https://doi.org/10.1016/j.cirp.2011.03.087

71. Sales WF, Schoop J, da Silva LRR, Machado ÁR, Jawahir IS (2020) A review of surface integrity in machining of hardened steels. J Manuf Process 58:136-162. https://doi.org/10.1016/j. jmapro.2020.07.040

Publisher's note Springer Nature remains neutral with regard to jurisdictional claims in published maps and institutional affiliations. 